\title{
Insights into the synergetic effect for co-pyrolysis of oil sands and biomass using microwave irradiation
}

DOI:

10.1016/j.fuel.2018.10.139

\section{Document Version}

Accepted author manuscript

Link to publication record in Manchester Research Explorer

\section{Citation for published version (APA):}

Li, H., Li, J., Fan, X., Li, X., \& Gao, X. (2019). Insights into the synergetic effect for co-pyrolysis of oil sands and biomass using microwave irradiation. Fuel, 239, 219-229. https://doi.org/10.1016/j.fuel.2018.10.139

\section{Published in:}

Fuel

\section{Citing this paper}

Please note that where the full-text provided on Manchester Research Explorer is the Author Accepted Manuscript or Proof version this may differ from the final Published version. If citing, it is advised that you check and use the publisher's definitive version.

\section{General rights}

Copyright and moral rights for the publications made accessible in the Research Explorer are retained by the authors and/or other copyright owners and it is a condition of accessing publications that users recognise and abide by the legal requirements associated with these rights.

\section{Takedown policy}

If you believe that this document breaches copyright please refer to the University of Manchester's Takedown Procedures [http://man.ac.uk/04Y6Bo] or contact uml.scholarlycommunications@manchester.ac.uk providing relevant details, so we can investigate your claim.

\section{OPEN ACCESS}


Elsevier Editorial System(tm) for Fuel Manuscript Draft

Manuscript Number: JFUE-D-18-03404R2

Title: Insights into the synergetic effect for co-pyrolysis of oil sands and biomass using microwave irradiation

Article Type: Research paper

Keywords: microwave, co-pyrolysis, synergetic effect, oil sands, biomass

Corresponding Author: Dr. Xin Gao, Ph.D.

Corresponding Author's Institution: Tianjin University

First Author: Hong Li, Ph.D.

Order of Authors: Hong Li, Ph.D.; Jing Li, Master; Xiaolei Fan, School of Chemical Engineering and Analytical Scie; Xingang Li, Ph.D.; Xin Gao, $\mathrm{Ph} . \mathrm{D}$.

Abstract: Microwave-assisted co-pyrolysis of oil sands and biomass (sawdust) was carried out for the first time to investigate the synergistic effect under microwave irradiation. In the co-pyrolysis process, the pyrolysis residues of sawdust serve as the effective microwave absorber to enable the improved thermal decomposition of oil sands compared with the case by the conventional thermal treatment. Effects of co-pyrolysis temperature, blending ratio, and feedstock-tomicrowave absorber ratio on the product distribution were examined. Compared with conventional (CV) co-pyrolysis, a synergetic effect, in terms of 10.9wt.\% higher gas yield and 8.3wt.\% lower liquid yield, was manifested during microwave (MW) co-pyrolysis. Biomass added to the feedstock promoted the generation of compounds with molecular weight $>800$ $\mathrm{Da}$ in the liquid products. MW radiation promoted 24.5 \% higher aromatic hydrocarbons on average, but 19.2\% fewer phenols in MW-generated oils, which are more desirable as value-added chemicals. Furthermore, chars produced by MW performed more porotic, contributing to positive recycling as absorbing materials. The thermochemical conversion of biomass with oil sand revealed that MW heating is a simple, effective, and alternative solution to increase the energy efficiency of co-pyrolysis process, maximizing the use of resources. 


\section{Dear Editors:}

We submit our manuscript entitled 'Insights into the synergetic effect for co-pyrolysis of oil sands and biomass using microwave irradiation' to 'Fuel' for publication. No conflict of interest exits in the submission of this manuscript, and manuscript is approved by all authors for publication. On behalf of my co-authors, I declare that the work submitted has not been published previously, and is not under consideration for publication elsewhere, in whole or in part. All the authors listed have approved the manuscript that is enclosed.

Microwave-assisted co-pyrolysis is a promising route to obtain value-added products. In this paper, co-pyrolysis of oil sands and sawdust integrating microwave irradiation was first carried out to investigate the synergistic effect and microwave influencing mechanism. We reused pyrolytic residues of biomass as microwave absorber. During co-pyrolysis, biomass added to the feedstock promoted the generation of high molecular compounds in the liquid products. In contrast to the conventional pyrolytic oils, higher aromatic hydrocarbons and lower oxygenated compounds generated in microwave-generated oils. Moreover, chars in microwave pyrolysis exhibited stereo and unconsolidated structure, performing good microwave absorption. Our findings may have general implications in oil upgrading and high quality chars producing.

We deeply appreciate your consideration of our manuscript, and we look forward to receiving comments from the reviewers. If you have any queries, please don't hesitate to contact me at the address below.

Thank you and best regards.

Sincerely yours,

Xin Gao,

Email: gaoxin@tju.edu.cn

Tel: +86-022-27404701(X.G.) 


\title{
Fuel
}

Reference manuscript JFUE-D-18-03404R1

\author{
Insights into the synergetic effect for co-pyrolysis of \\ oil sands and biomass using microwave irradiation \\ by Hong Li, Jing Li, Xiaolei Fan, Xingang Li, Xin Gao
}

Dear Editor,

Thank you so much for your letter. I am very pleased that you will consider our manuscript for publication in Fuel. Furthermore, we thank the reviewers for their valuable comments on our manuscript entitled "Insights into the synergetic effect for co-pyrolysis of oil sands and biomass using microwave irradiation". All the comments are very valuable and helpful for revising and improving our paper. We have considered the comments carefully and made more appropriate corrections which we trust to meet your approval. Revised portions are marked with red text in the paper. The detailed corrections in the paper and the responses to the reviewers' comments are listed point by point hereafter.

\section{Answers to reviewers' comments}

\section{Reviewer 1}

Comments: The author did interesting work carring out the microwave-assisted co-pyrolysis of oil sands and biomass firstly. Co-pyrolysis resulted in a higher gas yield and lower liquid yield than the single-material pyrolysis. The yields of MW-generated volatiles were higher than $\mathrm{CV}$-generated volatiles. Thermal decomposition behavior and determination of the final temperature, determination of additives, oil composition analysis and characterization of chars are investigated with different oprating conditions. This article provides a new route for the utilization of biomass, which has significant consequence.

Author reply: We thank the reviewer for the positive feedback and the constructive comments.

Comment 1: The English expression should be checked to avoid grammatical errors, for example, in the title of 3.3, yield is spelled as yeild.

Author reply: Thank you for reminding us about that. We are so sorry about these grammatical errors. We have checked the whole paper and corrected all the grammatical errors already, including the title of 3.3, "yeild" has been changed to "yield". Also, we have corrected some spelling mistakes and imperfect sentence patterns. .

\section{Reviewer 2}

Comments: This manuscript describes the experimental work for thermochemical conversion of biomass with fossil fuels. This topic has received considerable interests and the manuscript can be published with minor corrections suggested as follows:

Comment 1: Abstract and Conclusions can be improved by highlighting the novelty and some quantitative results.

Author reply: Thank you for your valuable suggestion. The novelty has been highlighted and some quantitative results have been added in Abstract and Conclusions. Changes in detail are shown as 
follows:

[Abstract]

1. In the co-pyrolysis process, the pyrolysis residues of sawdust serve as the effective microwave absorber to enable the improved thermal decomposition of oil sands compared with the case by the conventional thermal treatment. Effects of co-pyrolysis temperature, blending ratio, and feedstock-to-microwave absorber ratio on the product distribution were examined. Compared with conventional (CV) co-pyrolysis, a synergetic effect, in terms of $10.9 \mathrm{wt} . \%$ higher gas yield and $8.3 \mathrm{wt} . \%$ lower liquid yield, was manifested during microwave (MW) co-pyrolysis.

2. compounds with molecular weight $>800 \mathrm{Da}$;

3. MW radiation promoted $24.5 \%$ higher aromatic hydrocarbons on average, but $19.2 \%$ fewer phenols in MW-generated oils, which are more desirable as value-added chemicals. Furthermore, chars produced by MW performed more porotic, contributing to positive recycling as absorbing materials.

[Conclusions]

1. Results from this experimental study have shown the potential of MW radiation as a technically feasible pyrolysis choice for thermochemical conversion of biomass together with oil sands. Comparatively, MW-assisted co-pyrolysis produced lower liquid yield (by about $8.3 \%$ ), but more average gas yield, about $10.9 \%$ higher than that by the conventional heating method. The use of biomass pyrolysis residues, as good MW absorbers, is an economical and environmentally friendly method for promoting the co-pyrolysis.

2. Finally, the use of TG-DTG, MALDI-TOF-MS, GC-MS and BET analyses allows the reaction difference of microwave-assisted oil sands co-pyrolysis with biomass to be postulated. It is concluded in this study that the conversion of fossil fuels with biomass into higher-value energy products under microwave can potentially improve the application prospects of microwave pyrolysis technology.

Comment 2: Where is the thermocouple inside the reactor in the microwave heating experiment? Please clearly show it in Fig. 1. How much depth will be the sensor into the samples?

Author reply: Thank you for reminding us about that. We have showed it in Fig. 1 clearly along with a larger version of the sensor position on the side. In this experiment, we put the sensor into the $4 / 5$ depth (the height of feedstock is about $6 \mathrm{~cm}$ and the depth of the thermocouple is about $4.8 \mathrm{~cm}$ ) of the feedstocks (black ones marked with "feedstock" in Fig. 1). 


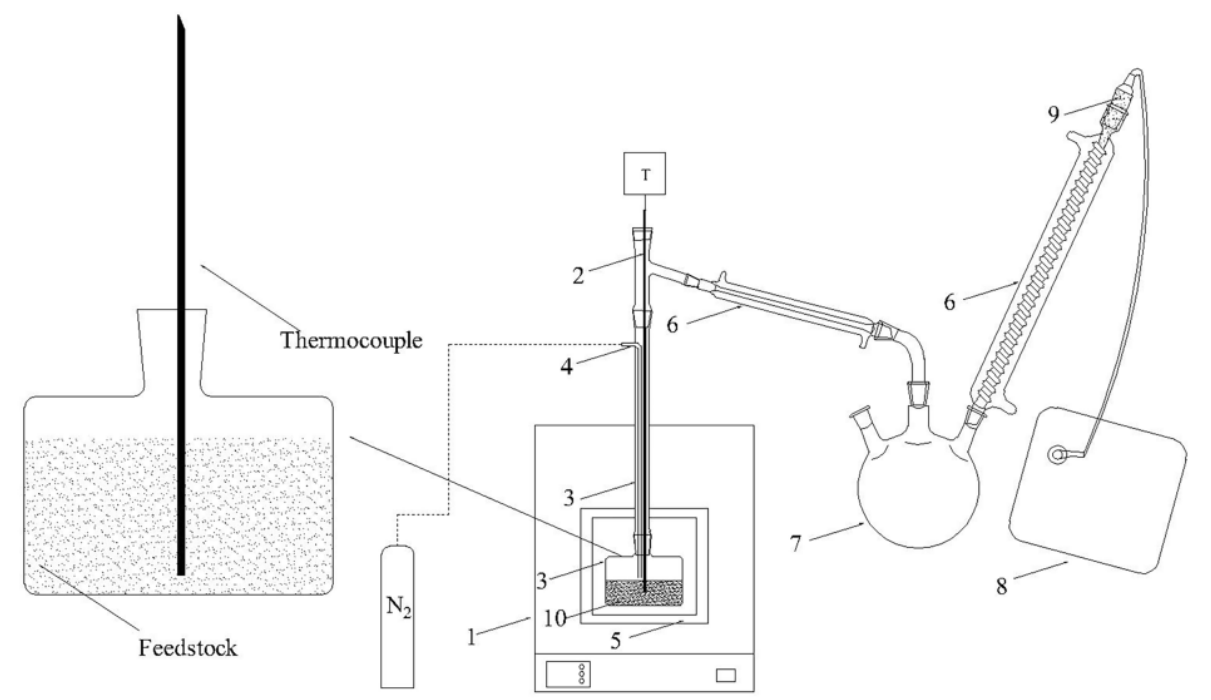

Fig. 1

Comment 3: Figure 13 is not very clear to read. It is better to change the color for the different components.

Author reply: Thank you for your suggestion. We have changed the color for the different components. After deleting two figures and reordering the figure number, you can see the final version shown as Fig.11.

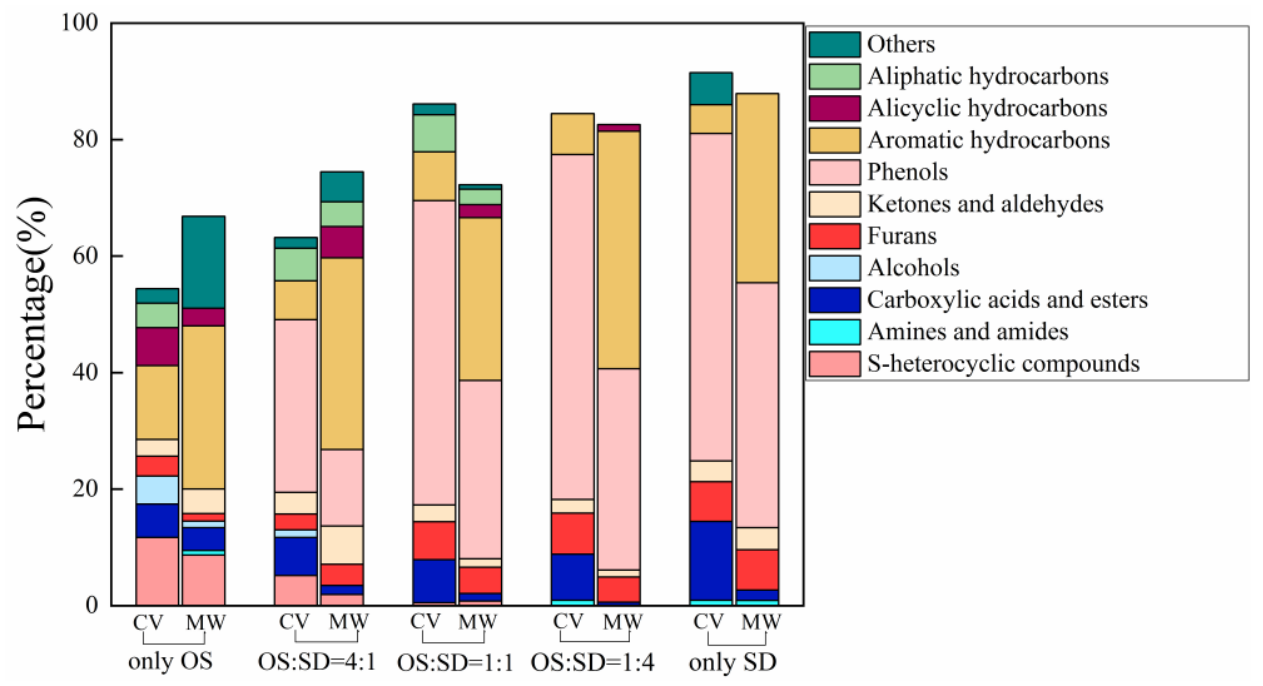

Fig.11

Comment 4: In line 308, which figure in Fig. 12 is referred to?

Author reply: Thank you for your question. After reordering the figure numbers, the discussions about product distributions in Fig.10 (e) are referred to and we have described it clearly in the paper.

Comment 5: The meaning of line 322-324 is not clear about the change of phenols contents.

Author reply: Thank you for your suggestion. "In detail, in only OS pyrolysis, no phenols were identified in GC-MS analysis. When blending ratios of SD during co-pyrolysis are 20.0\%, 50.0\%, 
$80.0 \%, 100.0 \%$, phenols in MW-generated oils decrease from $29.7 \%$ to $13.2 \%, 52.2 \%$ to $30.6 \%$, $59.2 \%$ to $34.6 \%$, $56.2 \%$ to $42.0 \%$, about $19.2 \%$ lower on average compared with CV pyrolytic oils." is added to illustrate the change of phenols contents. "Based on the feedstocks' characteristics and reaction conditions, pyrolytic oils mainly contained hydrocarbons, phenols, benzene derivatives, oxygenated compounds (furans and alcohols) and so on." is added to make the expression more clearly.

Comment 6: Please add the reference of the sentence in line 330-331, "higher yields of aromatic hydrocarbons is desirable for better quality of fuel".

Author reply: Thank you for reminding us about that. The expression "higher yields of aromatic hydrocarbons is desirable for better quality of fuel" was not very accurate. To some extent, higher content of aromatic hydrocarbon is desirable for better quality of fuel. Aromatic hydrocarbons existed in gasoline help to improve octane value. Also, they help to improve lubricating oils' viscosity-temperature performance and antioxidant capacity. However, more aromatic hydrocarbons in diesel oil are not desirable because of the low spontaneous ignition temperature, resulting in low cetane number and bad combustion performance. So we changed this expression into "Aromatic hydrocarbons are desirable for value-added chemicals and industrial feedstocks. So MW-generated oils which were rich in p-Xylene, indene, naphthalene and other aromatic hydrocarbons were desirable for obtaining recoverable energy and chemicals.".

\section{Reviewer 3}

Comments: This manuscript provides meaningful results in the aspects of microwave radiant pyrolysis and synergetic effect during co-pyrolysis process. The results obtained by TG, GC/MS and MALDI-TOF-MS are beneficial to explore the thermal decomposition mechanism of microwave radiation. However, there are still some problems in the manuscript that need to be revised or supplemented.

Author reply: We thank the reviewer for the positive recommendation and helpful comments.

Comment 1: Page 8, line 71: "molar ratio of $\mathrm{H} 2 / \mathrm{C}$ " should be "molar ratio of $\mathrm{H} / \mathrm{C}$ ".

Author reply: Thank you for reminding us about that. We have corrected it already.

Comment 2: Page 11, line 150: The capitalization of titles should be in a uniform format, such as section titles of 2.5.2 and 2.6.

Author reply: Thank you for reminding us about that. We regret having made such a mistake. We have corrected all the titles in a uniform format, including section titles of 2.5.2, 2.6 and 3.4.2.

Comment 3: Page 11, line 151-155: Whether the influence of matrix peaks is taken into account in the MALDI-TOFMS characterization? The procedure based on elimination of the interference of main matrix peaks in MALDI-TOF-MS characterization, as well as the semi-quantitative calculations which have not explicitly stated in the ref. 40 of the manuscript, should be explained in the experimental section or as a supplemental material.

Author reply: Thank you for your suggestion. We eliminated the influence of matrix peaks when calculating relative abundance to obtain the molecular distribution. Before, we had asked the author of ref. 40 about the specific explanation about the procedure and calculations. However, we 
did not show it in the paper. Now the procedure and the semi-quantitative calculations are explained in the experimental section. Generally, matrix peaks have relatively high peak intensity, which also appear in the same position in the peak spectra, that is, having same $\mathrm{m} / \mathrm{z}$. In this paper, matrix peaks include $\mathrm{m} / \mathrm{z}=135,154,272,317$, etc., which were determined by reordering the peak intensity from highest to lowest and finding out the matrix peaks according to the comparative study on all the peak intensity data. Based on the premise of eliminating these matrix peaks, firstly, we chose the strongest peak intensity as threshold value, and then "relative abundance" is expressed as a percentage figure - the ratio of the peak intensity value to the strongest peak intensity value. Secondly, molecular distribution is obtained by calculating the ratios of the sum of relative abundance in different molecular weight sections to the total relative abundance. Finally, the average molecular weight is taking a weighted average of the relative abundance values.

Comment 4: Page 15, line 237: A problem of the citation format, [35, 36, 37, 38, 39] should be changed to [35-39], as well as the citations in Page 16, line 250.

Author reply: Thank you for reminding us about that. We have corrected the two problems already.

Comment 5: Page 22, line 395 in the conclusion section: The experimental conditions of $75 \% \mathrm{SD}$ content are not mentioned in the above experiment.

Author reply: Thank you for reminding us about that. We are so sorry for making such a clerical error. "75\% SD" in Page 22, line 395 and Page 22, line 399 should be "80\% SD", that is, "OS(oil sands): $S D$ (sawdust) $=1: 4$ " as seen in Fig.10. It was caused by human error and deliberation. In this paper, the blending ratios of SD were set as $0.0 \%, 20.0 \%, 50.0 \%, 80.0 \%, 100.0 \%$, respectively, as it was much easier to calculate the specific value of SD weight. Actually, we did not do any experiments about $75 \%$ SD content. We have corrected the two same mistakes (Line 321 and Line 431) already.

Comment 6: Page 26, Table 1: The caption of Table 1 should be "Proximate and ultimate analyses of raw materials". The author should check again to confirm the data of proximate analysis. How can there be moisture under dry basis? In addition, the ash content in oil sands is very high, so the analysis of ash composition should be supplemented, and the influence of ash on pyrolysis should be evaluated. In addition, the ultimate analysis data seems to be in daf basis, not dry basis. The data of proximate analysis seems in air dry (ad) basis.

Author reply: Thank you for your suggestion.

1. The caption of Table 1 is adjusted to "Proximate and ultimate analyses of raw materials" and the caption of Table 3 is adjusted to "Ultimate analysis of char samples". Actually, the proximate analysis data is in air dry basis, not dry basis and the ultimate analysis data is in dry ash-free basis. In Line 105, "Prior to use, both the materials were dried at $105^{\circ} \mathrm{C}$ in an electrothermal constant-temperature dry box for 3h." , it was referred to the preparation of "standard samples" for the pyrolysis experiments. Prior to use, we dried the oil sands and biomass to reduce the effect of inherent water during co-pyrolysis. However, the proximate analysis based on air dry basis was used to analyze the content of inherent moisture, ash, volatiles and fixed carbon. So we chose the air dried samples which had inherent moisture, not the "standard samples". And it can explain that 
there can be moisture under proximate analysis. It is important to definitely point out the specific basis of the analytical methods as shown in Fig. a. We have added the annotations in Table 1 and Table 2.

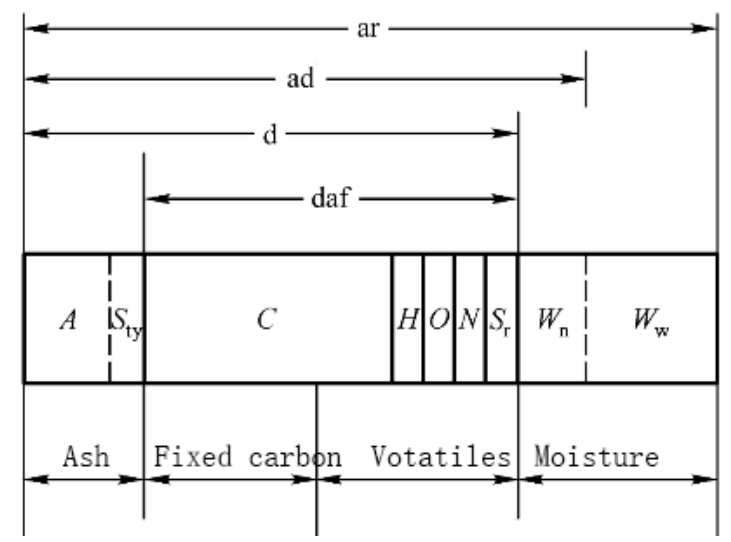

Fig. a. The specific basis of the analytical methods.

2. Ash is referred to incombustible minerals of fossil fuels. Generally, oil sand is a natural mixture of clays (minerals), bitumen (organics), and a small amount of water. Our oil sand samples were sourced from Buton, Indonesia, which contained only $27.3 \mathrm{wt} \%$ bitumen (by Soxhlet extraction) and the majority of oil sands is minerals. In "Zhang Z, Bei H, Li H, Li X, Gao X. Understanding the Co-Pyrolysis Behavior of Indonesian Oil Sands and Corn Straw. Energy Fuels 2017;31:2538-2547.", whose materials are same as ours, inorganic elements of oil sands are Ca, K, $\mathrm{Fe}, \mathrm{Mg}, \mathrm{Al}, \mathrm{P}, \mathrm{Si}, \mathrm{Ti}, \mathrm{Cl}, \mathrm{Ni}$. In "Nie F, He D, Guan J, et al. Oil sand pyrolysis: Evolution of volatiles and contributions from mineral, bitumen, maltene, and SARA fractions[J]. Fuel, 2018, 224:726-739.", the compositions of minerals of Indonesia oil sand include $\mathrm{CaO}, \mathrm{K}_{2} \mathrm{O}, \mathrm{Fe}_{2} \mathrm{O}_{3}$, $\mathrm{MgO}, \mathrm{Al}_{2} \mathrm{O}_{3}, \mathrm{P}_{2} \mathrm{O}_{5}, \mathrm{SiO}_{2}, \mathrm{TiO}_{2}$. Moreover, this article concluded by noting that, "According to the volatile evolution curves of raw oil sand and its bitumen, the effect of the mineral during pyrolysis of the two oil sand samples under the tested heating condition is small." and "The yield of volatiles during the different stages is greatly determined by the organic constituents of the oil sand.". Oil sand in our paper was sourced from Indonesia, whose minerals' compositions are similar with that in the above-mentioned literature. Therefore, the influence of ash on pyrolysis is limited in our paper. And we have added relevant description in Line 105.

Comment 7: Fig.2 is DTG, and Fig.3 is TG.

Author reply: Thank you for reminding us about that. We are sorry for that mistake and we have put the two figures in right order.

Comment 8: Figure 6 could be deleted because all data have been presented in Table 2.

Author reply: Thanks for your suggestion. We have deleted Figure 6.

Comment 9: The basis of data in Table 2 should be indicated. If the data is in air-dry basis, the data should be checked through element balance analysis.

Author reply: Thank you for reminding us about that. We did not calculate $\mathrm{O}$ content in the paper before, and we have added the $\mathrm{O}$ content in Table 2. The data has been checked through element balance analysis. Also, the basis of data in Table 2 is dry ash-free basis. We have added the annotations below Table 2 . 
Table 2. Ultimate analysis of char samples.

\begin{tabular}{ccccccc}
\hline Element Types & \multicolumn{2}{c}{ only oil sands } & \multicolumn{2}{c}{ oil sands : sawdust=1:1 } & \multicolumn{2}{c}{ only sawdust } \\
\cline { 2 - 7 } & $\mathrm{CV}$ & $\mathrm{MW}$ & $\mathrm{CV}$ & $\mathrm{MW}$ & $\mathrm{CV}$ & $\mathrm{MW}$ \\
\hline $\mathrm{C}^{c}$ & 20.63 & 19.76 & 41.64 & 34.18 & 91.84 & 87.65 \\
$\mathrm{H}^{c}$ & 0.10 & 0.18 & 0.42 & 0.90 & 0.85 & 0.86 \\
$\mathrm{~N}^{c}$ & 2.12 & 6.36 & 0.93 & 1.53 & 0.79 & 1.05 \\
$\mathrm{~S}^{c}$ & 1.27 & 1.63 & 1.14 & 1.48 & 0.25 & 0.18 \\
$\mathrm{O}^{b, c}$ & 75.88 & 72.07 & 55.87 & 61.91 & 6.27 & 10.26 \\
\hline
\end{tabular}

${ }^{b}$ By difference, ${ }^{c}$ dry ash-free basis.

Comment 10: Fig. 8 and Fig.9 are completely same data with different style, one could be deleted. Author reply: Thanks for your suggestion. We have deleted Figure 8.

Comment 11: Line 280-281, The AVMZ of individual OS pyrolysis and co-pyrolysis (blending ratio of $\mathrm{SD}$ is $80 \%$ ) are $416 \mathrm{Da}$ and $609 \mathrm{Da}$, respectively, which is against to the overall change trend. Why?

Author reply: Thanks for your question. The statement that "The AVMZ of individual OS pyrolysis and co-pyrolysis (blending ratio of SD is 80\%) are $416 \mathrm{Da}$ and $609 \mathrm{Da}$, respectively, which is against to the overall change trend." was not very accurate. We changed this sentence into "The AVMZ of microwave co-pyrolysis (blending ratio of SD is 20\%, 50\% and 80\%) are $391 \mathrm{Da}$, 404Da and $609 \mathrm{Da}$, respectively, which show no certain tendency. " and added "As known, microwave pyrolysis is a very complex thermal chemical conversion process, and a series of physical and chemical changes of the feedstocks occur. It has been reported that microwave interacted preferentially with polar oxygenates compared to non-polar alkanes[4] Also, microwave irradiation enhanced the relative volatility of high polarity substances, influencing the product composition[23]. Therefore, the product composition and the synergetic effect under microwave irradiation are different from the general rule, resulting in irregular trend of AVMZ. " in the paper. To ensure the data reliability, we did the analysis three times. So the data is definitely reliable. Also, the detailed information about the special synergetic effect and change of product composition under microwave irradiation will be further studied.

Comment 12: Line 295, "weitht"?

Author reply: Thank you for reminding us about that. We have checked the paper and corrected it already.

\section{Reviewer 4}

Comments: This paper gives some results on the co-pyrolysis of oil sand and biomass under microwave. The work is systematically, however, the manuscript is not well written and organized. Major amendments are needed before it could be accepted.

Author reply: Thanks for your suggestion. We have slightly adjusted the structure of the manuscript, seen in section 2.2, 2.3 and 2.4. Also, we have modified the language of the paper.

Comment 1: Line 71, molar ratio of "H/C" and "H-donors" are preferred.

Author reply: Thanks for your suggestion. We also think "H/C" and "H-donors" are preferred and 
have corrected in the paper.

Comment 2: Introduction, more information about the properties of oil sand and its co-pyrolysis with biomass or other feedstocks should be provided. The oil sand is a special carbon-containing fuels with high content of ash. The keypoint of this paper is microwave, if the materials are changed to coal and biomass, if the effect of microwave is the same as that of oil sand and biomass?

Author reply: Thanks for your suggestion. More information about the properties of oil sand is provided in introduction-"Oil sands, also known as tar sands or bituminous sands, are a class of natural mixtures of minerals, bitumen, and a small amount of water. Oil sands as the unconventional petroleum source are abundant worldwide, being attractive as an alternative energy supplement. To recover bitumen from the oil sands, current processing methods such as hot water extraction, organic solvent extraction, thermal treatment, direct combustion are used." However, few reports on co-pyrolysis of oil sands with biomass or other feedstocks, especially under microwave irradiation, are provided. Many articles have studied on co-pyrolysis of biomass with other materials (coal, petroleum residue, synthetic polymers, etc.). We have added two references in Line 75, that is "Zhang et al.[14] studied the co-pyrolytic behavior of oil sands and core straw in a drop tube fixed bed reactor under nitrogen atmosphere. Results showed that co-pyrolysis liquid product yield was increased, while the formation of solid residue was reduced. Yakup Kar[50] investigated the potential synergistic activities between tar sand and walnut shell during co-pyrolysis. The results indicated that the synergetic effect increased the co-pyrolysis bio-oil yield and its quality." . Also, microwave-assisted co-pyrolysis of coal with biomass were studied in many papers, having different conclusions. For example, "Zhang Y, Fan L, Liu S, et al. Microwave-assisted co-pyrolysis of brown coal and corn stover for oil production[J]. Bioresour Technol, 2018, 259." revealed that "Positive synergistic effect on oil yield was observed only at $C S / B C$ ratio of 0.33 and pyrolysis temperature of $600^{\circ} \mathrm{C} . "$ and "Positive synergistic effects were observed for ketones, aldehydes, acids and esters whereas negative synergistic effects for hydrocarbons, phenols and alcohols.". "An Y, Tahmasebi A, Yu J. Mechanism of synergy effect during microwave co-pyrolysis of biomass and lignite[J]. Journal of Analytical \& Applied Pyrolysis, 2017, 128. y." concluded that "During single-stage pyrolysis, the synergy effect promoted the formation of tar and gas products.". The effect of microwave irradiation depends on many factors, such as feedstock types, microwave power, carrier gas types. So it is difficult to judge the similarity and difference between oil sands and coal under microwave irradiation. The main purpose of this study is to investigate whether or not a synergetic effect occurs during the co-pyrolysis of biomass with oil sand in a lab-scale fixed-bed pyrolysis system and a microwave pyrolysis unit. So further study on the commonalities is needed. We will do more relevant researches in the future.

Comment 3: Lines 91-92, the proximate analysis of oil sand and biomass was according to GB/T 212 , which is the standard for coal analysis. Is it suitable for analysis of oil sand and biomass? I think there is standard for biomass analysis.

Author reply: Thanks for your suggestion. Generally, oil sands and coal both are fossil fuels which have similar compositions. Many articles about pyrolysis of oil sands have used the Chinese standard "GB/T 212-2008", such as "Nie F, He D, Guan J, et al. Oil sand pyrolysis: Evolution of 
volatiles and contributions from mineral, bitumen, maltene, and SARA fractions[J]. Fuel, 2018, 224:726-739." So it is suitable for analysis of oil sand. Actually, there is little difference between the analyses of oil sand and biomass. "GB/T 28731-2012" is more suitable for analysis of biomass. The methods based on "GB/T 28731-2012" of calculating moisture, volatiles and fixed carbon are the same as that "GB/T 212-2008", while calculating ash is different. The final temperature is set as $550 \pm 10^{\circ} \mathrm{C}(G B / T 28731-2012)$, while it is set as $815 \pm 10^{\circ} \mathrm{C}(G B / T 212-2008)$. When we used "GB/T 212-2008" before, the ashing is more complete than that "GB/T 28731-2012". So the content of ash maintains 1.05 when the standard is modified to "GB/T 28731-2012". We have corrected the description in the paper.

Comment 4: Lines 113-115, what is the meaning of this sentence? Did the author add the microwave absorbers in the feedstock? The detailed information is needed here.

Author reply: Thank you for reminding that. We have added the residues from only sawdust pyrolysis, serving as microwave absorber, in the feedstock. We have given the detailed information in Line 130, that is "Therefore, residues from the pyrolysis of SD (consist of carbon and small number of minerals) were used as microwave absorbers and blended into the feedstock (absorber/raw materials = 1:20).". Also, determination of additives was illustrated in detail in Line 223-237. Ultimate analysis showed that about $90 \%$ of the char is carbon. So we consider the residues from sawdust pyrolysis as carbonaceous susceptor.

Comment 5: Section 3.2, the biomass char is added to enhance the absorption of microwave, however, when the char is added, the pyrolysis system is complicated, and the role of added char except microwave absorber should be clarified.

Author reply: Thanks for your question. The main element of biomass char is carbon as shown in Table 2. Ultimate analysis showed that about $90 \%$ of the char is carbon. Energy dispersive spectrometry revealed that inorganic elements of chars include $\mathrm{Ca}, \mathrm{K}, \mathrm{Fe}, \mathrm{Mg}, \mathrm{Al}, \mathrm{P}, \mathrm{Si}, \mathrm{Ti}, \mathrm{Ni}$ and so on. The content of inorganic minerals and their oxides is very small in the char. So we think of char as "carbonaceous susceptor", having good microwave absorption. Carbonaceous susceptors like graphite and activated carbon were often used as used as microwave absorber in many articles. Such as "Menéndez J A, Inguanzo M, Pis J J. Microwave-induced pyrolysis of sewage sludge[J]. Water Research, 2002, 36(13):3261-3264.", "Salema A A, Ani F N. Microwave induced pyrolysis of oil palm biomass.[J]. Bioresource Technology, 2011, 102(3):3388-3395.", "Appleton, T.J., Colder, R.I., Kingman, S.W., Lowndes, I.S., Read, A.G., 2005. Microwave technology for energy-efficient processing of waste. Appl. Energy 81, 85-113." In this paper, chars were residues from complete sawdust pyrolysis, which had no potential to assist in pyrolyzing the feedstocks. However, slight minerals existed in the char may have little influence on the pyrolysis system. "Zhao X, Wang W, Liu H, et al. Temperature rise and weight loss characteristics of wheat straw under microwave heating[J]. Journal of Analytical \& Applied Pyrolysis, 2014, 107(9):59-66." concluded that " The pyrolytic residue contains metals such as $\mathrm{K}, \mathrm{Na}, \mathrm{Fe}$, etc., which act as catalysts for pyrolysis and/or other decomposition reactions such as decomposition of methane and thermal cracking of polymeric substances." As the pyrolysis system is complicated, the role of minerals in the char can be further studied. Our paper focused on comparing the pyrolysis characteristics between $\mathrm{CV}$ and MW pyrolysis and studying the synergetic effects by contrast experiments. In addition, all the contrast experiments were carried under same conditions. We 
added equal amounts of char to the feedstocks in all the experiments. We have added some future directions about studying effects of produced chars from pyrolysis in Line 373-378 in the paper.

Comment 6: The sequence of Fig. 5-7 should be adjusted from the text of section 3.2. In addition, the note of Fig. 5 should clearly show it is microwave assisted pyrolysis of conventional pyrolysis. Author reply: Thanks for your suggestion. We have adjusted the sequence of Figures. Also, we have added annotations in Figure 4-6 and Figure 13-14 clearly.

Comment 7: The title of section 3.3, yeilds=>yields

Author reply: Thank you for reminding us about this mistake. We have checked the whole paper and corrected all the grammatical errors like this already, including the spelling mistakes in Figures.

Comment 8: From Fig.8a, the liquid yield of MW is lower than that of $\mathrm{CV}$, then how to judge the effect of microwave? Is it better than CV? Did the author calculate the energy efficiency of microwave assisted pyrolysis?

Author reply: Thank you for your question. This paper concluded that a synergetic effect, in terms of higher gas yield and lower liquid yield, was manifested during microwave co-pyrolysis compared with conventional pyrolysis. "Liquid yield" is not the only judgement standard of the effect of microwave. To judge the effect of microwave, many factors should be considered, such as liquid yield (lower liquid yield under microwave irradiation may be not beneficial when focus on obtaining more pyrolytic oils), gas yield (higher gas yield under microwave irradiation may be beneficial for generating more syngas), oil compositions (higher aromatic hydrocarbons under microwave irradiation contribute to producing high-value chemicals), char samples (chars under microwave irradiation are more porous which may be beneficial for reusing as adsorbing materials). So we just focus on the differences between CV co-pyrolysis and WM co-pyrolysis, namely the synergetic effect. Furthermore, some detailed information will be given in analyzing the differences between microwave and conventional co-pyrolysis, which had not been studied before. In this study, the experimental phenomenon showed that products generated in microwave pyrolysis were much more than those of conventional pyrolysis at the temperatures of less than $300^{\circ} \mathrm{C}$, which are in accordance with the statement in "Huang Y F, Peite C, Wenhui $K$, et al. Microwave pyrolysis of lignocellulosic biomass: heating performance and reaction kinetics.[J]. Energy, 2016, 100:137-144." that "The weight losses of microwave pyrolysis were about 32\% higher than those of conventional pyrolysis at the temperatures of less than $300^{\circ} \mathrm{C}$." Also, it was concluded in the article that "At the lower temperatures, the biomass decomposition performance of microwave pyrolysis can be much better than that of conventional pyrolysis. Besides, this implies that the energy use efficiency of microwave pyrolysis could be higher than that of conventional pyrolysis by up to $32 \%$. " So in our study, the phenomenon indicated that the energy use efficiency of microwave is much higher than that of conventional pyrolysis. However, the calculation of energy efficiency should consider many factors, such as the conversion efficiency in turning electrical energy into microwave energy, microwave energy into heat energy, and heating efficiency of the conventional heating and so on. Extensive and complicated data is needed in the calculation. The calculation of energy efficiency is very important. The detailed researches on the calculation of energy efficiency may be further studied. 
Once again, we appreciate for editors/reviewers' warm work earnestly. If you have any question on the revisions, please do not hesitate to let us know.

Sincerely yours,

Xin Gao,

E-mail: gaoxin@tju.edu.cn

School of Chemical Engineering and Technology

Tianjin University, Tianjin 300072, China 
Pyrolytic residues were served as microwave absorbers recurrently;

A synergetic effect, higher gas yield and lower liquid yields, was manifested;

Higher aromatic hydrocarbons and lower oxygenated compounds generated in microwave-generated oils;

Microwave-generated chars performed as fine particles and exhibited unconsolidated structure. 
Graphical Abstract (for review)

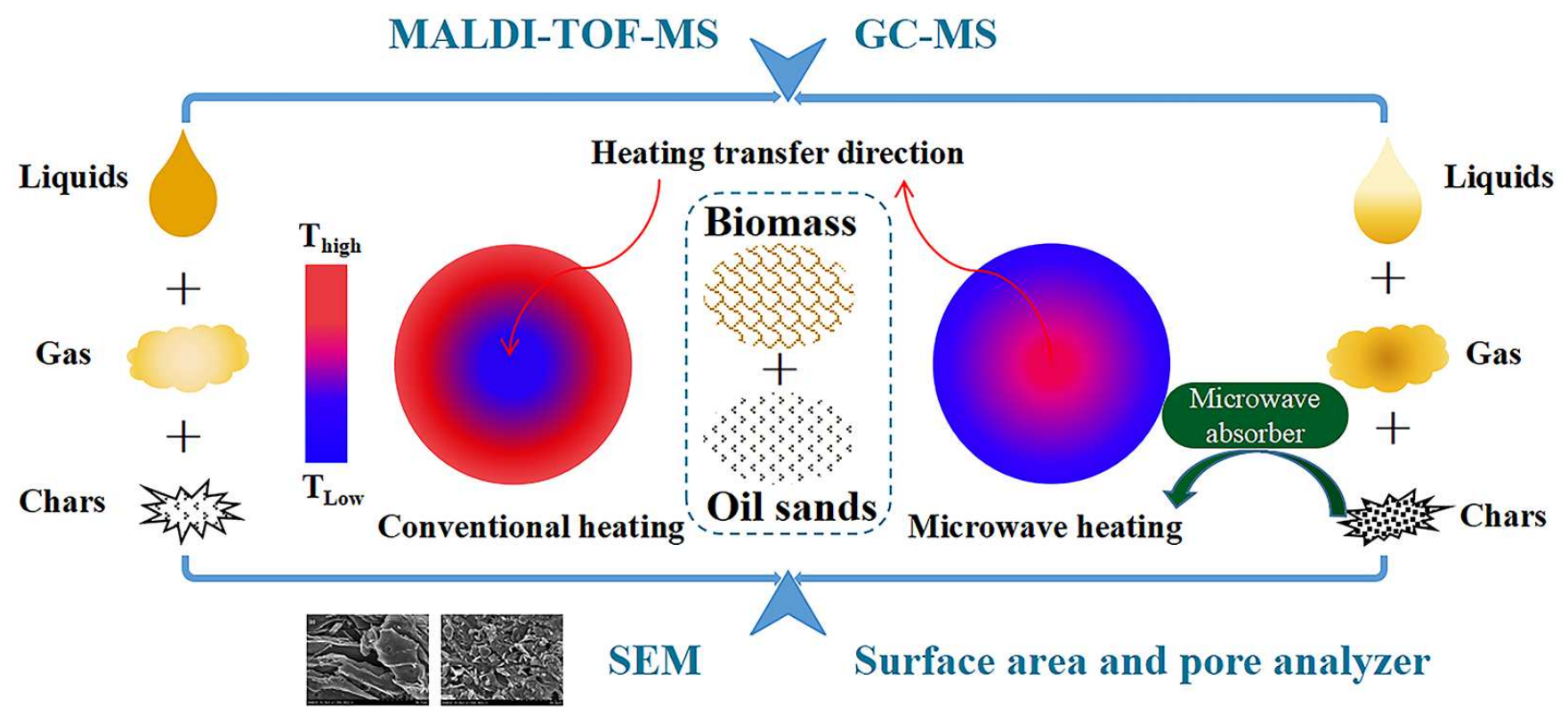




\title{
Insights into the synergetic effect for co-pyrolysis of oil sands
}

\section{and biomass using microwave irradiation}

\author{
Hong $\mathrm{Li}^{1}$, Jing $\mathrm{Li}^{1}$, Xiaolei $\mathrm{Fan}^{2}$, Xingang $\mathrm{Li}^{1}$, Xin Gao ${ }^{1,2, *}$ \\ ${ }^{1}$ School of Chemical Engineering and Technology, National Engineering Research Center of Distillation \\ Technology, Collaborative Innovation Center of Chemical Science and Engineering (Tianjin), Tianjin University, \\ Tianjin 300072, China \\ ${ }^{2}$ School of Chemical Engineering and Analytical Science, The University of Manchester, Oxford Road, Manchester, \\ M13 9PL, United Kingdom
}

Abstract: Microwave-assisted co-pyrolysis of oil sands and biomass (sawdust) was carried out for the first time to investigate the synergistic effect under microwave irradiation. In the co-pyrolysis process, the pyrolysis residues of sawdust serve as the effective microwave absorber to enable the improved thermal decomposition of oil sands compared with the case by the conventional thermal treatment. Effects of co-pyrolysis temperature, blending ratio, and feedstock-to-microwave absorber ratio on the product distribution were examined. Compared with conventional (CV) co-pyrolysis, a synergetic effect, in terms of $10.9 \mathrm{wt} . \%$ higher gas yield and $8.3 \mathrm{wt} . \%$ lower liquid yield, was manifested during microwave (MW) co-pyrolysis. Biomass added to the feedstock promoted the generation of compounds with molecular weight $>800 \mathrm{Da}$ in the liquid products. MW radiation promoted $24.5 \%$ higher aromatic hydrocarbons on average, but $19.2 \%$ fewer phenols in MW-generated oils, which are more desirable as value-added chemicals. Furthermore, chars produced by MW performed more porotic, contributing to positive recycling as absorbing materials. The thermochemical conversion of biomass with oil sand revealed that MW heating is a simple, effective, and alternative solution to increase the energy efficiency of co-pyrolysis process, maximizing the use of resources.

\footnotetext{
* Corresponding author. Tel: +86-022-27404701 (X.G.); Fax: +86-022-27404705 (X.G.).

E-mail: gaoxin@tju.edu.cn (Xin Gao).
} 
24 Keywords: microwave, co-pyrolysis, synergetic effect, oil sands, biomass

\section{1. Introduction}

26 Energy consumption of fossil fuels increases rapidly due to economic development and increase in

27 industrial production. It is essential to utilize alternative energy sources and convert renewable

28 sources into value-added chemicals or high-quality chars for the industry. Oil sands, also known as tar sands or bituminous sands, are a class of natural mixtures of minerals, bitumen, and a small amount of water. Oil sands as the unconventional petroleum source are abundant worldwide, being attractive as an alternative energy supplement. To recover bitumen from the oil sands, current processing methods such as hot water extraction, organic solvent extraction, thermal treatment, direct combustion are used. Recently, co-processing of oil sands with other resources has been increasingly drawing attention to industry. Biomass, a renewable and $\mathrm{CO}_{2}$ neutral energy source with low contents of sulfur, can be mixed with oil sands for chemical modification of obtained products. Pyrolysis process can be considered as a thermo-chemical conversion route to produce various chemicals and fuels. Several studies have been reported on conventional pyrolysis of oil sands, sawdust or the blends investigated that traditional heating is comparatively slow and inefficient. Moreover, conventional heating methods typically present a significant challenge for bulk materials such as biomass, with very limited heat convection. Also, any gains in heat transfer are offset by the need for more peripheral equipment, and inevitably a much higher capital cost[1].

43 Therefore, new technologies such as microwave-assisted pyrolysis have been proposed recently.

44 Microwave heating shows many advantages over conventional heating methods, such as rapid and efficient volumetric heating and selective heating, overcoming heat transfer constraints[1], and 
hence reducing the process time and energy consumption. In addition, the uniform temperature distribution[2,3] and simple heating system favourable for large-scale processing equipment[1]. Also, it has been reported that high polarity substances increased, while relatively low polarity substances decreased in the liquid products, suggesting that microwave irradiation enhanced the relative volatility of high polarity substances[23]. Therefore, microwave-assisted pyrolysis is a promising technology to obtain value-added products.

Previous studies showed that[4], in comparison with the conventional pyrolysis, microwave pyrolysis of coal produced more gaseous products and less tars, especially higher $\mathrm{CO} / \mathrm{CO}_{2}$ ratio and lower concentrations of polar oxygenates in oil tars. In addition, the gas from microwave treatment of coffee hulls has much higher $\mathrm{H}_{2}$ and syngas $\left(\mathrm{H}_{2}+\mathrm{CO}\right)$ contents[5]. The biochar obtained by the microwave-assisted catalytic pyrolysis of switchgrass showed an increase in BET surface area[6]. However, previous researches on microwave-assisted individual pyrolysis of fossil fuels and biomass indicated that many limitations existed in individual pyrolysis. For instance, lower $\mathrm{H} / \mathrm{C}$ ratio in low-rank coal results in lower tar yield[7], scattered distribution of biomass limits its extensive utilization[8], pyrolysis oils with high oxygen content perform low calorific value, corrosion problems and instability[9]. As a result, interests in upgrading the pyrolysis products have been growing recently. Co-pyrolysis is an entirely feasible technology for upgrading pyrolysis oil, char and gas in terms of operating conditions, reaction mechanism/process description, and technical feasibility[10]. However, different co-pyrolysis behaviors, also known as synergistic effect, are observed in various systems, which affected by blending ratios, heating rate, residence time, feedstock types, reactor types[11]. Positive synergistic effects from tar yield were observed under 25\% green algae/75\% low-rank coal co-pyrolysis[12], 50:50 lignite/corncob 

chloride blends[15], oil shale/plastics blends[16]. However, in terms of lower tar yields, negative synergistic effects were manifested in co-pyrolysis of rice straw/Leucaena leucocepha wood and sub-bituminous coal[17], sawdust/coal blends at lower temperature range[18]. Lack of synergetic effects performed in the pyrolytic characteristics of woody biomass/coal blends[19]. Therefore, understanding of synergistic effects during co-pyrolysis is still limited. Further research on the product distribution and properties is still needed.

Cellulose and hemicellulose components of biomass can produce hydrogen by secondary reactions, and polymerizing reactions caused by lignin in biomass form reactive radicals, which contributes to depolymerizing coal by cleaving methylene bridges[20]. Previous reports revealed that the high molar ratio of $\mathrm{H} / \mathrm{C}$ in biomass could act as $\mathrm{H}$-donors and this hydrogen transfer reaction provokes the synergistic positive effect, producing more volatile products[11, 21, 22]. Zhang et al.[14] studied the co-pyrolytic behavior of oil sands and core straw in a drop tube fixed bed reactor under nitrogen atmosphere. Results showed that co-pyrolysis liquid product yield was increased, while the formation of solid residue was reduced. Yakup Kar[50] investigated the potential synergistic activities between tar sand and walnut shell during co-pyrolysis. The results indicated that the synergetic effect increased the co-pyrolysis bio-oil yield and its quality. Thus it is desirable to co-pyrolysis oil sands and biomass to modify product distributions and minimize the impact of individual pyrolysis of petroleum fuels on the environment.

87 The aim of this paper is to understand the synergetic effect from the differences in product distributions and compositions between CV co-pyrolysis and MW co-pyrolysis. Another goal of this study was to investigate the co-pyrolysis behaviour under MW pyrolysis since it has been 
seldom researched. Sawdust was selected as typical renewable feedstock and co-pyrolyzed with oil sands at different blending ratios for the purpose of obtaining convincible and reliable experimental results. A combined application of matrix-assisted laser desorption ionization time of flight mass spectra (MALDI-TOF-MS) and gas chromatography-mass spectrometer (GC-MS) were to characterize the specific physicochemical properties. Then, ultimate analysis, scanning electron microscopy (SEM) and surface area and pore analyzer were applied to understand disparities in surface morphology and micro structure of solid products.

\section{Materials and methods}

\subsection{Materials}

Oil sands (OS) from Buton, Indonesia and Sawdust (SD) from Liaoning province, China were chosen as raw materials in this study. The samples were crushed and sieved into particles with diameters less than $1.0 \mathrm{~mm}$. The proximate analysis of raw oil sands was conducted in accordance with the National Standard of China (GB/T 212-2008), while of sawdust was based on GB/T 28731-2012. The ultimate analysis was carried out using an element analyzer (Vario EL cube, Elementar, Germany). All analytical results were shown in Table 1. High content of ash in Indonesia oil sand has little influence in pyrolysis[52]. Prior to use, both the materials were dried at $105^{\circ} \mathrm{C}$ in an oven for $3 \mathrm{~h}$.

\subsection{Thermogravimetric analysis of raw samples}

Thermogravimetric Analysis (TGA/DSC1, Mettler Toledo, Switzerland) was performed under the nitrogen flow $(100 \mathrm{ml} / \mathrm{min})$ to assess the thermostability of materials. The temperature ramp used was from room temperature to $1100^{\circ} \mathrm{C}$ at a heating rate of $100^{\circ} \mathrm{C} / \mathrm{min}$ and $250^{\circ} \mathrm{C} / \mathrm{min}$, respectively, to explore the final temperature under microwave pyrolysis. 


\subsection{Microwave (MW) pyrolysis experiment}

113 A multimode on-off microwave oven[23] with a $2.45 \mathrm{GHz}$ frequency and maximum power output

114 of $800 \mathrm{~W}$ was utilized for the MW pyrolysis experiments. The schematic diagram of the MW

115 pyrolysis unit is shown in Fig. 1. All the joints of the tubes and vessels of the MW system were 99.999\%) was purged into the system at a specific flow rate to maintain an inert atmosphere. The modified thermocouple was also inserted into the reaction vessel via the quartz tube to measure on and switched to a predetermined microwave power for $1 \mathrm{~h}$ pyrolysis. During the experiment, a microwave detector (MKX-M1B) was used to monitor microwave leakage for safety purpose. products was collected using gas sampling bags. Due to the high viscosity of liquid products, there were some adhesive oils on the wall of condenser. The methods of washing adhesive oil and calculating the weight of the liquid, gas, solid products are detailed in previous study[14]. $100.0 \%$ ), was introduced into the reactor. Since oil sands and sawdust are not good microwave absorbers, requiring additives such as the activated carbon to facilitate the pyrolysis. Therefore, 
that during co-pyrolysis no reaction occurs between the two raw materials, the calculated total product yields should change linearly with increasing sawdust concentration. To identify possible synergistic effect in the co-pyrolysis process, the specific calculation process was defined as shown in Eq (1).

$$
Y_{\mathrm{cal}, i}=Y_{O S, i}(1-\alpha)+Y_{S D, i} \alpha
$$

where $Y_{\text {cal }, i}$ is the calculated yield of product i (liquid, gas and char) during co-pyrolysis, $Y_{O S, i}, Y_{S D, i}$ are the calculated yields of individual oil sands pyrolysis and individual sawdust pyrolysis, respectively, and $\alpha$ is the mass fraction of sawdust in the feedstock. All the experiments were repeated non-consecutively three times to evaluate the repeatability of results.

\subsection{Conventional (CV) pyrolysis experiment}

The CV pyrolysis experiments were carried out in a fixed-bed reactor heated by a temperature-programmed furnace under comparable experimental conditions to MW pyrolysis experiments. The experiment apparatus and the detailed procedure are described elsewhere[14]. In brief, the same amount of raw materials was put into the reactor tube, purged with $\mathrm{N}_{2}$ gas at a same flow rate. The samples were heated to $700^{\circ} \mathrm{C}$ under a $20^{\circ} \mathrm{C} / \mathrm{min}$ heating rate, and then maintain at $700^{\circ} \mathrm{C}$ for 30 minutes. The same method as used in the MW pyrolysis experiment was performed to calculate the mass of oil and char.

\subsection{Oil fractionation and composition analysis}

\subsubsection{Oil fractionation}

Co-pyrolytic products as a mixture of water, pyrolytic lignin, polycyclic aromatic hydrocarbons and other organic compounds have to be fractionated into different solvents prior to chemical characterization. It was proved that pyrolysis oils were completely soluble in tetrahydrofuran 
(THF) but exhibited relatively lower solubility in dichloromethane and chloroform, likely because of high water content and high proportion of pyrolytic lignin[24]. Therefore, THF was used as the solvents for matrix-assisted laser desorption ionization time of flight mass spectra (MALDI-TOF-MS) analysis to obtain the molecular weight distribution. The dichloromethane preferentially dissolve the lower boiling/smaller analytes which are subject to GC/MS analysis.

\subsubsection{MALDI-TOF-MS analysis}

The molecular weight distribution of the liquids was analyzed by a Bruker matrix-assisted laser desorption ionization time of flight mass spectra (MALDI-TOF-MS) (Autoflex tof/tofIII, Bruker, USA). The 2,5-Dihydroxybenzoic acid (DHB) was used as matrix. The obtained liquid samples were diluted with THF to a ratio of 1:10, 1:100 and 1:1000. The obtained MALDI-TOF-MS spectrum is shown in Fig. S. 1.

\subsubsection{GC-MS analysis}

The chemical compositions of products dissolved in dichloromethane were determined by an Agilent gas chromatography-mass spectrometer (7890GC-5977MS, Agilent Technologies, USA) equipped with HP-5 capillary column ( $30 \mathrm{~m} \times 250 \mu \mathrm{m} \times 0.25 \mu \mathrm{m})$. Dichloromethane-extracts were dried by anhydrous sodium sulfate, and then filtration is made with $0.45-\mu \mathrm{m}$ microfilters. The initial GC oven temperature was set to $50{ }^{\circ} \mathrm{C}$ and maintained for $3 \mathrm{~min}$, and then increased to $250{ }^{\circ} \mathrm{C}$ at $10{ }^{\circ} \mathrm{C} / \mathrm{min}$ and held for $30 \mathrm{~min}$. High purity helium (99.99\%) was applied as the carrier gas at a flow rate of $3 \mathrm{~mL} / \mathrm{min}$. The inject volume was $1 \mu \mathrm{L}$ with a split ratio of $25: 1$. The injector, the ion source, and the MS transfer line were kept at a constant temperature of 280, 230, and $280^{\circ} \mathrm{C}$, respectively. Main chemical compounds corresponding to each peak in oil chromatograms were identified by using NIST98 mass spectral database. 
178

\subsection{Characterizations of chars}

Ostensible changes in surface morphology properties and elemental compositions of char samples were analyzed by the scanning electron microscopy (SEM, S-4800, Janpan) with energy dispersive spectrometry (EDS). Pore structure determination and surface area of char samples were tested by Tristar 3000 surface area and pore analyzer (ASAP 2020/Tristar 3000, USA). The specific surface area was determined according to the Brunauer-Emmett-Teller (BET) theory. The BET surface area and adsorption average pore diameter were calculated by t-plot method, and the total pore volume was derived by single point adsorption total pore volume at $\mathrm{P} / \mathrm{P}_{0}$ of 0.99 .

\section{Results and discussion}

\subsection{Thermal decomposition behavior and determination of the final}

\section{temperature}

TG curves and differential calculations of the weight loss (DTG) of the raw materials were shown in Fig. 2 and Fig. 3. The pyrolysis process of oil sand can be summarized as three stages: water evaporation, devolatilization and decomposition of residues[25]. The mass loss under $200^{\circ} \mathrm{C}$ corresponds to the evaporation of water, which is sightly lower than the moisture content by the proximate analysis. Thermal decomposition appears to start at $200-300^{\circ} \mathrm{C}$. For the pyrolysis with oil sands only, One main decomposition stage happens in the temperature range of $300-500^{\circ} \mathrm{C}$, and a second decomposition stage happens at between around $750-900{ }^{\circ} \mathrm{C}$, as $\mathrm{CaCO}_{3}$ in sands decomposed at this temperature. For the sawdust pyrolysis only, hemicellulose decomposes firstly due to its structure instability, and then cellulose, lignin, together with hemicellulose, decompose into low molecular compounds at $200^{\circ} \mathrm{C}-500^{\circ} \mathrm{C}$. No distinct changes in mass are observed above $700^{\circ} \mathrm{C}$, since the char, whose major component was carbonaceous species, could withstand high 
OS. However, only one DTG peak happens from individual pyrolysis. The maximum weight loss of SD was at $400{ }^{\circ} \mathrm{C}$, while around $500{ }^{\circ} \mathrm{C}$ for individual $\mathrm{OS}$ pyrolysis, resulting in two different DTG peaks during co-pyrolysis.

In addition, coupled with TG results in elsewhere[14], different heating rates have evident effects in the pyrolysis process. With an increasing heating rate, the TG curve and the DTG peak shift to a higher temperature region and the mass-loss process happens in a shorter time at a higher heating rate. This shift, resulting in delayed decomposition, may be ascribed to the combined effects of the heat transfer at the different heating rates and the kinetics of the decomposition[26]. As heating rate increases, both the activation energy and pre-exponential factor increase[27]. This may contribute to the changes of product distributions under CV and MW pyrolysis with different heating rates discussed as follows.

The product yields from co-pyrolysis as a function of temperature was investigated, with the oil sands to sawdust ratio being 1:1 and additives (residues from only sawdust pyrolysis) to feed ratio being 1:20. As shown in Fig. 4, the char yields show a sustained reduction but the total amount of liquid and gas yields increase due to the primary pyrolysis and higher secondary reaction at a higher temperature, which contributes to generating plenty of gaseous products. Though the final 217 temperature was set as $1100^{\circ} \mathrm{C}$, the actual measured temperature maintained at around $900^{\circ} \mathrm{C}$, 218 resulting in similar product distributions when the final temperature was set as $900^{\circ} \mathrm{C}$. To save 219 energy, mitigate the production of environmentally unfriendly gases and inhibit the decomposition of $\mathrm{CaCO}_{3}$ as much as possible, it can be inferred that $700^{\circ} \mathrm{C}$ was the optimal final temperature for 221 the MW pyrolysis experiment. Meanwhile, the pyrolysis of oil sands and sawdust were thoroughly 
performed under $700^{\circ} \mathrm{C}$.

\subsection{Determination of additives}

224 Both the oil sands and sawdust have poor dielectric properties and thus perform weak microwave 225 absorption capability. Without the presence of microwave absorbers, the maximum temperatures attainable by oil sands and sawdust under MW irradiation was about 235 and $387{ }^{\circ} \mathrm{C}$, respectively, as shown in Fig. 5. To achieve high temperatures in several minutes and remove the volatiles from the surface of raw materials, effective microwave receptors, such as activated carbon, char from pyrolysis, some metal oxides or silicon carbide were essential to be mixed with feedstock[28]. mixed could heat up to $700^{\circ} \mathrm{C}$ within 200 s. The higher efficiency and shorter heating time of residues from only SD pyrolysis were attributed to the fact that residues exhibited relatively higher carbon content (Table 2) than that from only $\mathrm{OS}$ and $\mathrm{OS}: \mathrm{SD}=1: 1$ pyrolysis. Carbon has high dielectric properties and performs as good microwave absorber in other report[29]. Thus, residues from only SD pyrolysis, considered as carbon, were reused as microwave receptors instead of other additives due to their good microwave absorption in this paper. Furthermore, the cyclic utilization of residues significantly save energy and processing cost.

\subsection{Product yields from co-pyrolysis under MW and CV}

239 The calculated and experimental product yields obtained from MW and CV blends at $700^{\circ} \mathrm{C}$ were performed in Fig. 7 successively. The general production trend shows that as the blending ratio of

241 SD increases, the total amount of liquid and gas (volatiles) yields monotonically increases, while 

generating plenty of $\mathrm{H}$ and $\mathrm{OH}$ radicals which also act as $\mathrm{H}_{2}$-donors during co-pyrolysis.

246 Recombination and repolymerisation (cross-linking) reactions of free radicals that increase char

247 formation are suppressed by the H-transferring behavior in the blends, therefore, the liquid and gas

248 yields increase[30-32]. For both MW and CV, the experimental liquid yields are generally lower 249 than calculated ones with negative synergetic effect. On the contrary, the experimental gas yields 250 are exceeding calculated yields, may be due to the increase in secondary reactions and conversion 251 of tar to gas in co-pyrolysis[33]. At a fixed reaction time, the experimental and theoretical results are close to each other with respect to the char yields, and almost no synergies happened. However,

253 it has been reported that the remarkable increase of liquid products yield indicated the existence of 254 positive synergetic effect. Since the magnitude of the synergetic effect on the volatile yield varies 255 with operating conditions such as final temperature, heating rate, blending ratio of biomass, 256 biomass type[34]. As shown in Fig. 7, the disparity between MW and CV is recognized, 257 suggesting that synergetic effect differs under different conditions. The average liquid yield of 258 MW is 21.8 wt.\%, about $8.3 \%$ lower than that in $\mathrm{CV}$, but the average gas yield shows an opposite 259 trend, about $10.9 \%$ higher in contrast to $\mathrm{CV}$, and with respect to char yield, the two calculated curves and experimental points are identical. The variation in product distribution is identified

261 with previous reports[24,35-39]. It was reported that volatile materials with high polarity and 262 dielectric constant escaped from the surface were selectively heated by microwave and converted 263 into gas, which contributed to a higher gas yield and a lower liquid yield[4]. During co-pyrolysis, 264 the temperature of $700^{\circ} \mathrm{C}$ reached within several minutes in the microwave oven, however, it 265 takes $34 \mathrm{~min}$ in the fixed bed reactor when the samples were heated from $20^{\circ} \mathrm{C}$ to $700^{\circ} \mathrm{C}$ under a 

mechanism, MW heating shows great heating efficiency.

\subsection{Oil composition analysis}

A series of material pictures are exhibited in Fig. 8. The disparities in clarity and colour of liquid pyrolysis, a yellow gas will be seen to escape into the condenser tube quickly and fiercely.

272 Condensable liquid products, composed of water, hydro-soluble compounds and oil, are luminous

273 and show significantly layered phenomenon after enough setting. However, during CV pyrolysis,

274 yellow gas escaped out gently, and then it condensed into troubled liquor, without obvious layering. The liquid product performed as emulsions after sufficient standing under CV pyrolysis.

\subsubsection{Molecular weight distribution}

277 The liquid products derived from CV and MW co-pyrolysis were complex mixtures of organic compounds. A semi-quantitative analysis was performed by calculating the average mass-to-charge $(\mathrm{m} / \mathrm{z})$ of each component (AVMZ) under CV and MW co-pyrolysis. The specific

"relative abundance" is expressed as a percentage figure - the ratio of the peak intensity value to

the strongest peak intensity value. Secondly, molecular distribution is obtained by calculating the

ratios of the sum of relative abundance in different molecular weight sections to the total relative abundance values, with results shown in Fig. 9 and Fig.10.

287 As can be seen in Fig.9, the AVMZ increases from $457 \mathrm{Da}(\mathrm{m} / \mathrm{z})$ to $566 \mathrm{Da}$ under individual 
attributes to the high proportion of less volatile and nonvolatile, high-molecular-weight components that include pyrolytic lignin in bio-oils[41]. Some research has been performed on bio-oils to detect the specific molecular weight distribution. Bio-oil compounds had molecular masses in the range of $\sim 100-800 \mathrm{Da}$, while the petroleum or heavy petroleum fractions had narrower $\mathrm{m} / \mathrm{z}$ range[42]. So it is reasonable that the AVMZ increases when more SD was blended in feedstocks. Compared with CV pyrolysis, no obvious increasing trend was observed with blending ratio of SD increases under MW pyrolysis. The AVMZ of microwave co-pyrolysis (blending ratio of SD is $20.0 \%, 50.0 \%$ and $80.0 \%$ ) are $391 \mathrm{Da}, 404 \mathrm{Da}$ and $609 \mathrm{Da}$, respectively, which show no certain tendency. As known, microwave pyrolysis is a very complex thermal chemical conversion process, and a series of physical and chemical changes of the feedstocks occur. It has been reported that microwave interacted preferentially with polar oxygenates compared to non-polar alkanes[4] Also, microwave irradiation enhanced the relative volatility of high polarity substances, influencing the product composition[23]. Therefore, the product composition and the synergetic effect under microwave irradiation are different from the general rule, resulting in irregular trend of AVMZ. In addition, discrepancies in AVMZ between CV and strongly affected by the pyrolysis process conditions. As reported in elsewhere[4], the interaction between electromagnetic radiations originated from microwave power and raw materials depends on many factors, such as temperature, microwave power and frequency, material permittivity and permeability. In the microwave-assisted co-pyrolysis experiments, oil sands and sawdust, with complex matrix of asphalt oil, sands, bio-oil, minerals, interact with magnetic field. The differences in product compositions may depend on the thermal effect and non-thermal effect 
caused by MW radiation. However, the detailed mechanism is insensible at present and needs to be explored in the future.

313 The columns exhibited in Fig. 10 indicated that the products are observed in the range of $314 \sim 100-1500$ Da with a peak at $\sim 200-500$ Da. GC-MS analysis[14] confirmed that major pyrolytic 315 compounds in oil sands were aromatic hydrocarbons and aliphatic hydrocarbons, with relatively 316 low molecular weight. Moreover, the majority of components in sawdust pyrolytic products 317 existed as oligomers[43], with higher molecular weight, resulting in different molecular weight distributions as SD added to. All the values of liquid yields conformed to a similarly Gaussian distribution. As blending ratio of SD increases, peak height becomes increasingly low and entire curve is tending towards a gentle gaussian curve. The distributions of raw materials mixed with

$32180 \%$ SD and 100\% SD are much broader than those of other studied situations. As shown in Fig. 10 (d) and (e), plenty of compounds with molecular weight $>800 \mathrm{Da}$ were found in products as majority of raw materials were sawdust. Meanwhile, small molecular compounds with <100 Da were much more in $\mathrm{OS}: \mathrm{SD}=1: 4$, only $\mathrm{SD}$ pyrolysis than that in $\mathrm{OS}: \mathrm{SD}=4: 1$ and only $\mathrm{OS}$ pyrolysis.

325 More biomass added to the feedstock promoted the yields of light molecular weight phenols, methylphenol, dimethylphenol, guaiacols and their derivatives in oil[44]. For one thing, high oxygen content in biomass resulted in more water in the products, contributing to more small 328 molecular components found out in the distribution. For another, high proportion of high 329 molecular weight components that include pyrolytic lignin in the aqueous phase coincide with the 330 results shown in Fig. 10 (e). The two curves obtained by Gaussian fitting display molecular weight 331 distributions more straightforwardly. Overall distribution trends under MW pyrolysis show many 332 similarities with that under $\mathrm{CV}$ pyrolysis. However, peak ranges perform difference, especially for 

only SD pyrolysis.

335

\subsubsection{GC-MS analysis}

The extracts from pyrolysis oil obtained during pyrolysis were analyzed by GC-MS for determining the major components. The dichloromethane soluble analytes mainly consisted of major components in pyrolysis oils. The detailed list of identified compounds was displayed in the Tables S.1-S.10 (in Supplementary file). As shown in Fig. 11, the identified compositions were divided into different groups according to characteristic functional groups or structure. Based on the feedstocks' characteristics and reaction conditions, pyrolytic oils mainly contained hydrocarbons, phenols, benzene derivatives, oxygenated compounds (furans and alcohols) and so on. Generally, S-heterocyclic compounds and aromatic hydrocarbons account for a large proportion in only OS pyrolytic oil, while a large quantity of phenols exist in only SD pyrolytic oil. Moreover, the proportion of aromatic hydrocarbons and phenols in MW-generated liquid products differs from that in CV-generated products. Phenols, furans and alcohols contents, also classified as oxygenated compounds, are all lower than that under CV pyrolysis. In detail, in only OS pyrolysis, no phenols were identified in GC-MS analysis. When blending ratios of SD during co-pyrolysis are $20.0 \%, 50.0 \%, 80.0 \%, 100.0 \%$, phenols in MW-generated oils decrease from $29.7 \%$ to $13.2 \%, 52.2 \%$ to $30.6 \%, 59.2 \%$ to $34.6 \%, 56.2 \%$ to $42.0 \%$, about $19.2 \%$ lower on average compared with $\mathrm{CV}$ pyrolytic oils. Phenols, with relatively higher dielectric constant than hydrocarbons, could be selectively heated by microwave power through a Debye-type mechanism, leading to decomposition, and then lowering their proportions[4]. The results are in line with the characteristics of MW heating. However, aromatic hydrocarbons increase from $12.7 \%$ to $28.0 \%$, 

aromatic hydrocarbons were desirable for obtaining recoverable energy and chemicals. It was also molecules, such as long-chain, branched-chain, and heterocyclic compounds and convert them into small-molecule fractions[45]. This may contribute to explaining the composition difference between MW and CV pyrolysis.

\subsection{Characterization of chars}

364 As can be seen from Table 2, the contents of C, H, N and S were comparable in the pyrolytic chars. Compared with CV-generated chars, the relatively lower carbon and hydrogen ratios for the MW pyrolytic chars are observed and could be due to self-gasification of residual carbon, which also resulting in higher gas yields. It was reported that the blended char during co-pyrolysis showed high gasification reactivity compared to coal-char alone[46]. Thus, the disparity in carbon content of OS:SW=1:1 is highest due to gasification reaction in MW pyrolysis. Moreover, it should be noted that the char compositions in the bituminous coal are quite different from those of oil sands. And the sulfur content in SD char samples was almost as low as that in raw SD. Sulfates in raw SD, mainly potassium or calcium sulfates, are very stable and cannot decompose before $900^{\circ} \mathrm{C}$. However, the adding of SD diminished the nitrogen content in the char samples. Energy dispersive spectrometry revealed that inorganic elements of chars include $\mathrm{Ca}, \mathrm{K}, \mathrm{Fe}, \mathrm{Mg}, \mathrm{Al}, \mathrm{P}, \mathrm{Si}$, 
379 Scanning electron microscope (SEM) micrographs of the char samples derived at three different

380 blends under CV and MW pyrolysis are shown in Fig. 12. Same magnification offered good 381 optical observation to compare the difference between CV and MW pyrolysis. Overall, the surface 382 morphology of char samples shows complexity and no uniform. The surface morphology of 383 conventional chars performs blocky shape, while that of microwave-chars exhibits stereo and 384 unconsolidated structure. Furthermore, more fine particles and mesopores are found on the surface 385 of chars from MW pyrolysis, but conventional chars perform big particle aggregates. As different 386 from heat transferring from the surface to center of a sample under CV pyrolysis, MW heating, 387 producing rapid, efficient in-core volumetric heating, transfers heat from the surface to the inside 388 of the sample. The heating characteristic affects the modification of surface morphology and 389 particle size during co-pyrolysis, and then the modification would influence the adsorption of the 390 reaction agent, the gasification or combustion performance of the co-pyrolysis char[46]. It was 391 found that new mesopores would be formed in the char and enlarged due to cross-linking as the 392 moisture volatilizes[47]. Similar results are reported that the direction of moisture volatilization 393 consistent with the direction of microwave energy transferring, resulting in more cracks formed 394 layer by layer from inside to outside[48].

395 Pore structure distribution and specific surface area were identified by $\mathrm{N}_{2}$ adsorption technique.

396 Isotherms exhibited in Fig. 13, displaying a type- II isotherm with H4 hysteresis based on the the 397 International Union of Pure and Applied Chemistry (IUPAC) classification, indicated that complex pore structures were found in chars. The inflection point of the isotherm usually occurs near the monolayer adsorption. As the relative pressure continues to increase, multi-layer adsorption 

porosity and specific surface area[49]. As expected, chars from only SD and OS:SD=1:1 using

402 MW method have much higher $\mathrm{N}_{2}$ adsorption, indicating that microwave radiation helped in

403 performing more porotic chars, which coincided with the surface morphology analysis.

404 The pore size distributions are illustrated in Fig. 14 and the highest peak in all figures were confirmed as interference peaks. According to the UIPAC classification, pores can be divided into three types, namely, pores with diameters smaller than $2 \mathrm{~nm}$ are micropores, those between 2 and 50nm are mesopores and macropores with larger than 50nm[4]. Steeper peaks are observed from are much more than that in CV-generated chars. During microwave volumetric heating, more from 2-4nm are less in OS:SD=1:1 and only OS pyrolysis.

The results of BET surface area, single point adsorption total pore volume of pores and adsorption average pore diameter are shown in Table 3. Generally, three parameters of the MW-generated

417 chars are higher than the case of $\mathrm{CV}$-generated chars. Moreover, most notable difference in surface 418 area (respectively $49.9 \mathrm{~m}^{2} / \mathrm{g}$ and $10.0 \mathrm{~m}^{2} / \mathrm{g}$ ) was observed in only SD pyrolysis. This result 419 corresponds with the conclusion in elsewhere [4].

\section{Conclusions}

421 In this work, MW-assisted co-pyrolysis of biomass with oil sands was investigated to understand 
the product distributions and compositions in comparison to that by the conventional co-pyrolysis.

423 Results from this experimental study have shown the potential of MW radiation as a technically

424 feasible pyrolysis choice for thermochemical conversion of biomass together with oil sands.

425 Comparatively, MW-assisted co-pyrolysis produced lower liquid yield (by about 8.3\%), but more

426

427

428

429

430

431

432

433

434

435 found on the surface of chars from MW pyrolysis and exhibited stereo and unconsolidated

436 structure, but conventional chars performed big particle aggregates. Besides, recycling of porous

437 MW-produced chars as MW absorbers is environmentally friendly. Finally, the use of TG-DTG,

438 MALDI-TOF-MS, GC-MS and BET analyses allows the reaction difference of

439 microwave-assisted oil sands co-pyrolysis with biomass to be postulated. It is concluded in this

440 study that the conversion of fossil fuels with biomass into higher-value energy products under

441 microwave can potentially improve the application prospects of microwave pyrolysis technology,

442

as microwave irradiation is effective and energy efficient in areas of oil upgrading and high quality

443 chars producing. 
444

445

446

447

448

449

450

451

452

453

454

455

456

457

458

459

460

461

462

463

464

465

466

467

468

469

470

471

472

473

474

475

476

477

478

479

480

\section{Acknowledgements}

The authors are grateful for the financial support from the National Natural Science Foundation of China (No. 21878219), the National Key Research and Development Program of China (2016YFB0301802). X. Gao thanks the China Scholarship Council (CSC, File No. 201706255020)

for his academic visiting fellowship in the UK, and X. Fan thanks the partial support by The Royal

Society International Exchange Award (IE161344) to enable the collaboration.

\section{References:}

[1] Robinson J, Dodds C, Stavrinides A. Microwave Pyrolysis of Biomass: Control of Process Parameters for High Pyrolysis Oil Yields and Enhanced Oil Quality. Energy Fuels 2015;29:1701-1709.

[2] Jones DA, Lelyveld TP, Mavrofidis SD, Kingman SW, Miles NJ. Microwave heating applications in environmental engineering — a review. Resour Conserv Recy 2002;34:75-90.

[3] Thostenson ET, Chou TW. Microwave processing: fundamentals and applications. Compos Part A-Appl S 1999;30:1055-1071.

[4] Abdelsayed V, Shekhawat D, Smith MW, Link D, Stiegman AE. Microwave-assisted pyrolysis of Mississippi coal: A comparative study with conventional pyrolysis. Fuel 2018;217:656-667.

[5] Domínguez A, Menéndez JA, Fernández Y, Pis JJ, Nabais JMV, Carrott PJM, et al. Conventional and microwave induced pyrolysis of coffee hulls for the production of a hydrogen rich fuel gas. J Anal Appl Pyrol 2007;79:128-135.

[6] Mohamed BA, Kim CS, Ellis N, Bi X. Microwave-assisted catalytic pyrolysis of switchgrass for improving bio-oil and biochar properties. Bioresource Technol 2016;201:121-132.

[7] Wu Z, Yang W, Tian X, Yang B. Synergistic effects from co-pyrolysis of low-rank coal and model components of microalgae biomass. Energy Convers Manage 2017;135:212-225.

[8] Meng HY, Wang SZ, Chen L, Wu ZQ, Zhao J. Study on product distributions and char morphology during rapid co-pyrolysis of platanus wood and lignite in a drop tube fixed-bed reactor. Bioresource Technol 2016;209:273-281.

[9] Qiang L, Li WZ, Zhu XF. Overview of fuel properties of biomass fast pyrolysis oils. Energy Convers Manage 2009;50:1376-1383.

[10] Uzoejinwa BB, He X, Wang S, El-Fatah Abomohra A, Hu Y, Wang Q. Co-pyrolysis of biomass and waste plastics as a thermochemical conversion technology for high-grade biofuel production: Recent progress and future directions elsewhere worldwide. Energy Convers Manage 2018;163:468-492.

[11] Quan C, Gao N. Copyrolysis of Biomass and Coal: A Review of Effects of Copyrolysis Parameters, Product Properties, and Synergistic Mechanisms. Biomed Res Int 2016;2016:1-11.

[12] Wu Z, Yang W, Li Y, Yang B. Co-pyrolysis behavior of microalgae biomass and low-quality coal: Products distributions, char-surface morphology, and synergistic effects. Bioresource Technol 2018;255:238-245.

[13] Sonobe T, Worasuwannarak N, Pipatmanomai S. Synergies in co-pyrolysis of Thai lignite and corncob. Fuel Process Technol 2008;89:1371-1378.

[14] Zhang Z, Bei H, Li H, Li X, Gao X. Understanding the Co-Pyrolysis Behavior of Indonesian Oil Sands and 
Corn Straw. Energy Fuels 2017;31:2538-2547.

[15] Dai M, Xu H, Yu Z, Fang S, Chen L, Gu W, et al. Microwave-assisted fast co-pyrolysis behaviors and products between microalgae and polyvinyl chloride. Appl Therm Eng 2018;136:9-15.

[16] Aboulkas A, Makayssi T, Bilali L, El Harfi K, Nadifiyine M, Benchanaa M. Co-pyrolysis of oil shale and plastics: Influence of pyrolysis parameters on the product yields. Fuel Process Technol 2012;96:209-213.

[17] Krerkkaiwan S, Fushimi C, Tsutsumi A, Kuchonthara P. Synergetic effect during co-pyrolysis/gasification of biomass a ndsub-bituminous coal. Fuel Process Technol 2013;115:11-18.

[18] Park DK, Kim SD, Lee SH, Lee JG. Co-pyrolysis characteristics of sawdust and coal blend in TGA and a fixed bed reactor. Bioresource Technol 2010;101:6151-6156.

[19] Meesri C, Moghtaderi B. Lack of synergetic effects in the pyrolytic characteristics of woody biomass/coal blends under low and high heating rate regimes. Biomass Bioenerg 2002;23:55-66.

[20] Lalvani SB, Muchmore CB, Koropchak JA, Akash B, Chavez C, Rajagopal P. Coal liquefaction in lignin-derived liquids under low severity conditions. Fuel 1991;70:1433-1438.

[21] Sharypov VI, Beregovtsova NG, Kuznetsov BN, Cebolla VL, Collura S, Finqueneisel G, et al. Influence of reaction parameters on brown coal-polyolefinic plastic co-pyrolysis behavior. J Anal Appl Pyrol 2007;78:257-264.

[22] Ishaq M, Ahmad I, Shakirullah M, Khan MA, Rehman HU, Bahader A. Pyrolysis of some whole plastics and plastics-coal mixtures. Energy Convers Manage 2006;47:3216-3223.

[23] Li H, Shi P, Fan X, Gao X. Understanding the influence of microwave on the relative volatility used in the pyrolysis of Indonesia oil sands. Chinese J Chem Eng 2018; 26:1485-1492.

[24] Harman-Ware AE, Ferrell JR. Characterization of catalytic fast pyrolysis oils: The importance of solvent selection for analytical method development. J Anal Appl Pyrol 2018;132:190-199.

[25] Wang Q, Jia C, Jiang Q, Wang Y, Wu D. Pyrolysis model of oil sand using thermogravimetric analysis. J Therm Anal Calorim 2014;116:499-509.

[26] Vamvuka D, Kakaras E, Kastanaki E, Grammelis P. Pyrolysis characteristics and kinetics of biomass residuals mixtures with lignite. Fuel 2003;82:1949-1960.

[27] Meng, Hu H, Zhang Q, Li X, Wu B. Pyrolysis Behaviors of Tumuji Oil Sand by Thermogravimetry (TG) and in a Fixed Bed Reactor. Energy Fuels 2007;21:2245-2249.

[28] Menéndez JA, Arenillas A, Fidalgo B, Fernández Y, Zubizarreta L, Calvo EG, et al. Microwave heating processes involving carbon materials. Fuel Process Technol 2010;91:1-8.

[29] Sun J, Wang W, Yue Q, Ma C, Zhang J, Zhao X, et al. Review on microwave-metal discharges and their applications in energy and industrial processes. Appl Energ 2016;175:141-157.

[30] Zhang L, Xu S, Zhao W, Liu S. Co-pyrolysis of biomass and coal in a free fall reactor. Fuel 2007;86:353-359.

[31] Krerkkaiwan S, Fushimi C, Tsutsumi A, Kuchonthara P. Synergetic effect during co-pyrolysis/gasification of biomass and sub-bituminous coal. Fuel Process Technol 2013;115:11-18.

[32] Moghtaderi B, Meesri C, Wall TF. Pyrolytic characteristics of blended coal and woody biomass. Fuel 2004;83:745-750.

[33] Yuan S, Dai Z, Zhou Z, Chen X, Yu G, Wang F. Rapid co-pyrolysis of rice straw and a bituminous coal in a high-frequency furnace and gasification of the residual char. Bioresource Technol 2012;109:188-197.

[34] Sonobe T, Worasuwannarak N, Pipatmanomai S. Synergies in co-pyrolysis of Thai lignite and corncob. Fuel Process Technol 2008;89:1371-1378.

[35] Chen M, Wang J, Zhang M, Chen M, Zhu X, Min F, et al. Catalytic effects of eight inorganic additives on pyrolysis of pine wood sawdust by microwave heating. J Anal Appl Pyrol 2008;82:145-150.

[36] Miura M, Kaga H, Sakurai A, Kakuchi T, Takahashi K. Rapid pyrolysis of wood block by microwave heating. 
J Anal Appl Pyrol 2004;71:187-199.

[37] Huang YF, Kuan WH, Lo SL, Lin CF. Total recovery of resources and energy from rice straw using microwave-induced pyrolysis. Bioresource Technol 2008;99:8252-8258.

[38] Wan Y, Chen P, Zhang B, Yang C, Liu Y, Lin X, et al. Microwave-assisted pyrolysis of biomass: Catalysts to improve product selectivity. J Anal Appl Pyrol 2009;86:161-167.

[39] Zhou R, Lei H, Julson J. The effects of pyrolytic conditions on microwave pyrolysis of prairie cordgrass and kinetics. J Anal Appl Pyrol 2013;101:172-176.

[40] Zhang L, Hu S, Chen Q, Xiao L, Syed-Hassan SSA, Jiang L, et al. Molecular structure characterization of the tetrahydrofuran-microwave-extracted portions from three Chinese low-rank coals. Fuel 2017;189:178-185.

[41] Harman-Ware AE, Ferrell JR. Characterization of catalytic fast pyrolysis oils: The importance of solvent selection for analytical method development. J Anal Appl Pyrol 2018;132:190-199.

[42] Staš M, Chudoba J, Kubička D, Blažek J, Pospíšil M. Petroleomic Characterization of Pyrolysis Bio-oils: A Review. Energy Fuels 2017;31:10283-10299.

[43] Scholze B, Meier D. Characterization of the water-insoluble fraction from pyrolysis oil (pyrolytic lignin). Part I. PY-GC/MS, FTIR, and functional groups. J Anal Appl Pyrol 2001;60:41-54.

[44] Song Y, Tahmasebi A, Yu J. Co-pyrolysis of pine sawdust and lignite in a thermogravimetric analyzer and a fixed-bed reactor. Bioresource Technol 2014;174:204-211.

[45] Yang Z, Zhu J, Li X, Luo D, Qi S, Jia M. Experimental Investigation of the Transformation of Oil Shale with Fracturing Fluids under Microwave Heating in the Presence of Nanoparticles. Energy Fuels 2017;31:10348-10357.

[46] Wu Z, Yang W, Meng H, Zhao J, Chen L, Luo Z, et al. Physicochemical structure and gasification reactivity of co-pyrolysis char from two kinds of coal blended with lignocellulosic biomass: Effects of the carboxymethylcellulose sodium. Appl Energ 2017;207:96-106.

[47] Ania CO, Parra JB, Menéndez JA, Pis JJ. Effect of microwave and conventional regeneration on the microporous and mesoporous network and on the adsorptive capacity of activated carbons. Micropor Mesopor Mat 2005;85:7-15.

[48] Le T, Ju S, Koppala S, Peng J, Pan B, Zhang L, et al. Kinetics study of microwave enhanced reactions between diasporic bauxite and alkali solution. J Alloy Compd 2018.

[49] Shui H, Shan C, Cai Z, Wang Z, Lei Z, Ren S, et al. Co-liquefaction behavior of a sub-bituminous coal and sawdust. Energy 2011; 36: 6645-6650.

[50] Kar, Y. Co-pyrolysis of walnut shell and tar sand in a fixed-bed reactor. Bioresource Technol 2011; 102.20:9800-9805.

[51] Zhao X, Wang W, Liu H, et al. Temperature rise and weight loss characteristics of wheat straw under microwave heating[J]. J Anal Appl Pyrol 2014; 107(9):59-66.

[52] Nie F, He D, Guan J, et al. Oil sand pyrolysis: Evolution of volatiles and contributions from mineral, bitumen, maltene, and SARA fractions[J]. Fuel 2018; 224:726-739. 
Table 1. Proximate and ultimate analyses of raw materials.

\begin{tabular}{ccc}
\hline & Oil sands $($ wt $\%)$ & Sawdust(wt\%) \\
\hline $\mathrm{C}$ & Ultimate analysis (dry ash-free basis) \\
$\mathrm{H}$ & $82.43^{a}$ & 48.83 \\
$\mathrm{~N}$ & $9.32^{a}$ & 6.56 \\
$\mathrm{~S}$ & $0.92^{a}$ & 7.93 \\
$\mathrm{O}$ & $4.39^{a}$ & 0.32 \\
& $2.94^{a, b}$ & $36.36^{b}$ \\
\hline moisture & Proximate analysis (air dry basis) $^{a}$ & 2.59 \\
ash & 1.22 & 1.05 \\
volatiles & 71.17 & 79.25 \\
fixed carbon & 26.78 & 17.11 \\
\hline
\end{tabular}

${ }^{a}$ Data from elsewhere[14], ${ }^{b}$ By difference.

Table 2. Ultimate analysis of char samples.

\begin{tabular}{ccccccc}
\hline Element Types & \multicolumn{2}{c}{ only oil sands } & \multicolumn{2}{c}{ oil sands : sawdust=1:1 } & \multicolumn{2}{c}{ only sawdust } \\
\cline { 2 - 7 } & $\mathrm{CV}$ & $\mathrm{MW}$ & $\mathrm{CV}$ & $\mathrm{MW}$ & $\mathrm{CV}$ & $\mathrm{MW}$ \\
\hline $\mathrm{C}^{c}$ & 20.63 & 19.76 & 41.64 & 34.18 & 91.84 & 87.65 \\
$\mathrm{H}^{c}$ & 0.10 & 0.18 & 0.42 & 0.90 & 0.85 & 0.86 \\
$\mathrm{~N}^{c}$ & 2.12 & 6.36 & 0.93 & 1.53 & 0.79 & 1.05 \\
$\mathrm{~S}^{c}$ & 1.27 & 1.63 & 1.14 & 1.48 & 0.25 & 0.18 \\
$\mathrm{O}^{b, c}$ & 75.88 & 72.07 & 55.87 & 61.91 & 6.27 & 10.26 \\
\hline \multicolumn{7}{c}{ By difference, ${ }^{c}$ dry ash-free basis. }
\end{tabular}

Table 3. Pore structure parameters of the char samples.

\begin{tabular}{cccc}
\hline & $\mathrm{S}_{\mathrm{BET}}\left(\mathrm{m}^{2} / \mathrm{g}\right)$ & $\mathrm{D}_{\text {avergage }}(\mathrm{nm})$ & $\mathrm{V}_{\text {total }}\left(\mathrm{cm}^{3} / \mathrm{g}\right)$ \\
\hline CV-only OS & 11.8416 & 3.4441 & 0.0102 \\
MW-only OS & 11.9516 & 4.3492 & 0.0130 \\
CV-OS:SD=1:1 & 22.6153 & 3.7413 & 0.0212 \\
MW-OS:SD=1:1 & 29.4506 & 5.2278 & 0.0385 \\
CV-only SD & 10.0030 & 3.0222 & 0.0076 \\
MW-only SD & 49.8681 & 3.1472 & 0.0392 \\
\hline
\end{tabular}




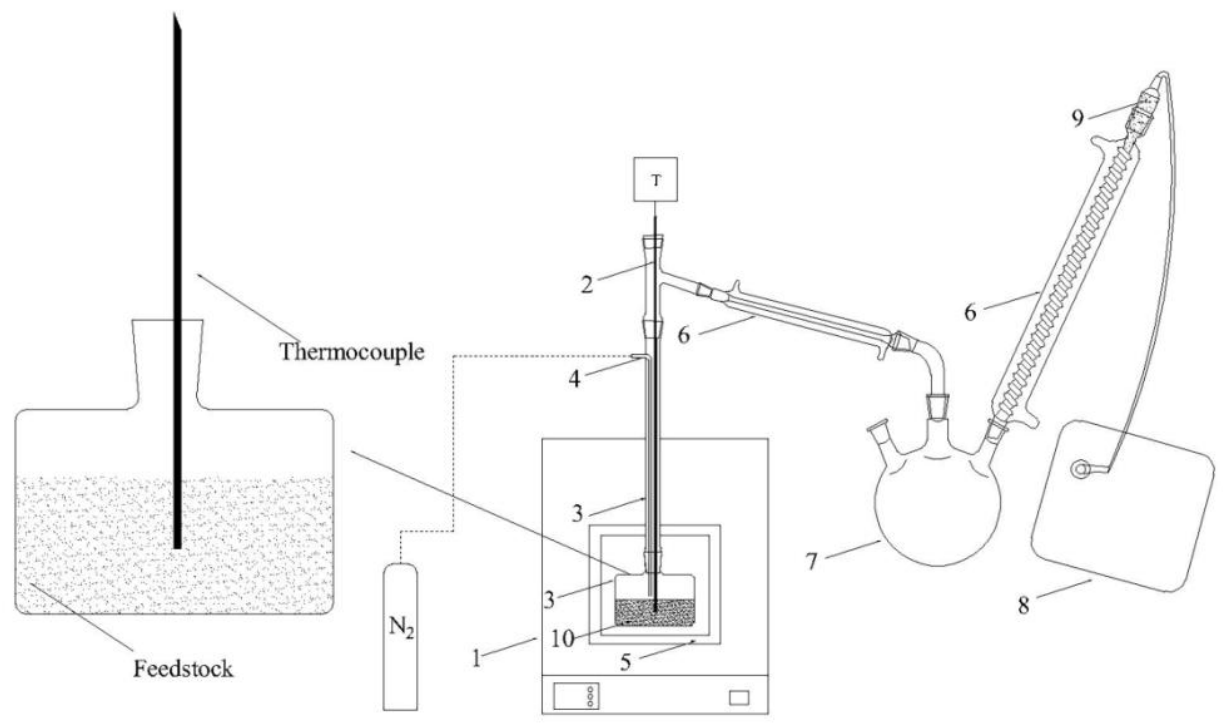

Fig. 1. Schematic diagram of the overall microwave pyrolysis unit, (1)microwave oven; (2)modified thermocouple; (3)quartz reactor and tube; (4)tube for nitrogen purging; (5)glass wool insulation; (6)condensers; (7)three-necked flask; (8)gas sampling bag; (9)cotton; (10)feedstock.

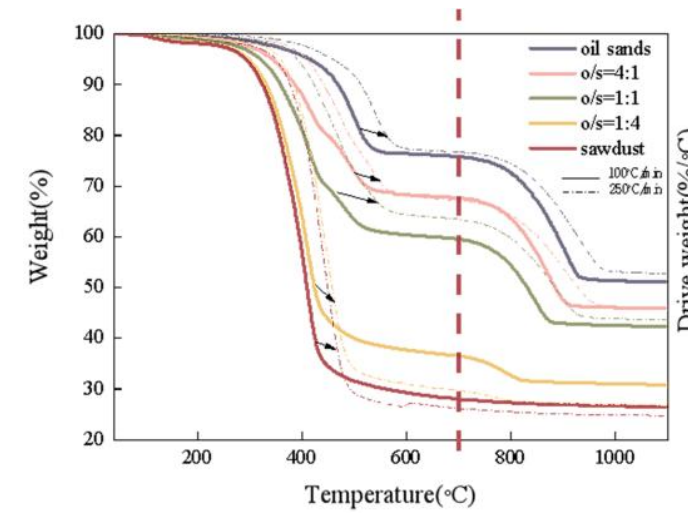

Fig. 2. TG curves of oil sands, sawdust, and their blends with different blending ratios at heating rate of 100 and $250{ }^{\circ} \mathrm{C} / \mathrm{min}$.

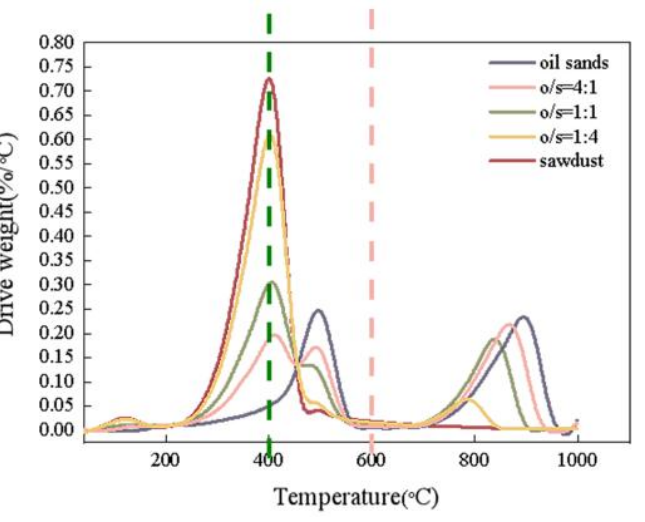

Fig. 3. DTG curves of different feedstocks at $100{ }^{\circ} \mathrm{C} / \mathrm{min}$.

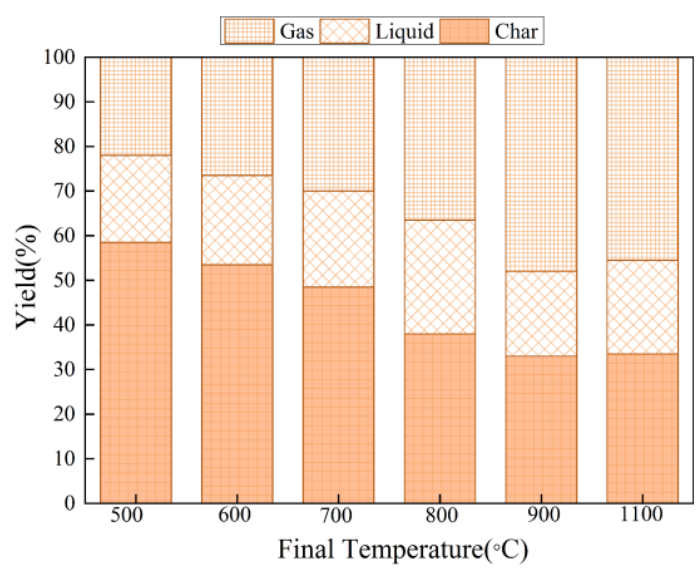

Fig. 4. The effect of final temperature on liquid, gas and char yields during microwave co-pyrolysis.

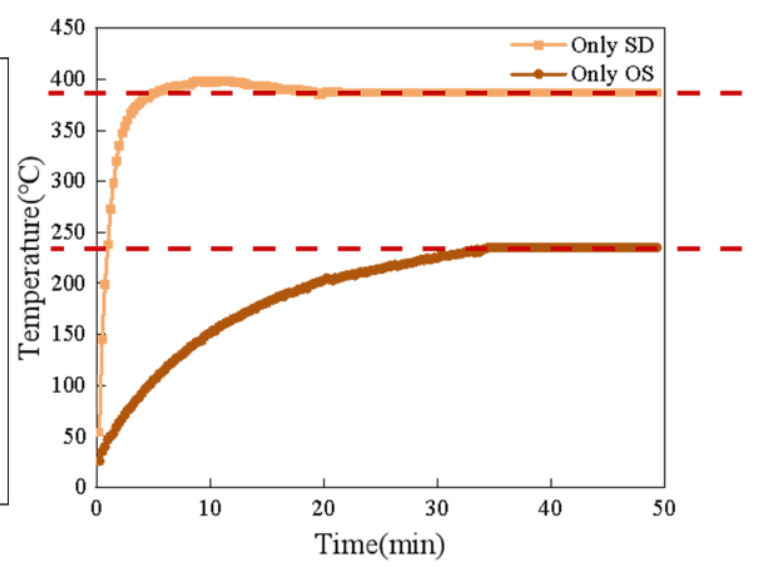

Fig. 5. Temperature profiles of only OS and SD pyrolysis without absorbers during microwave co-pyrolysis. 


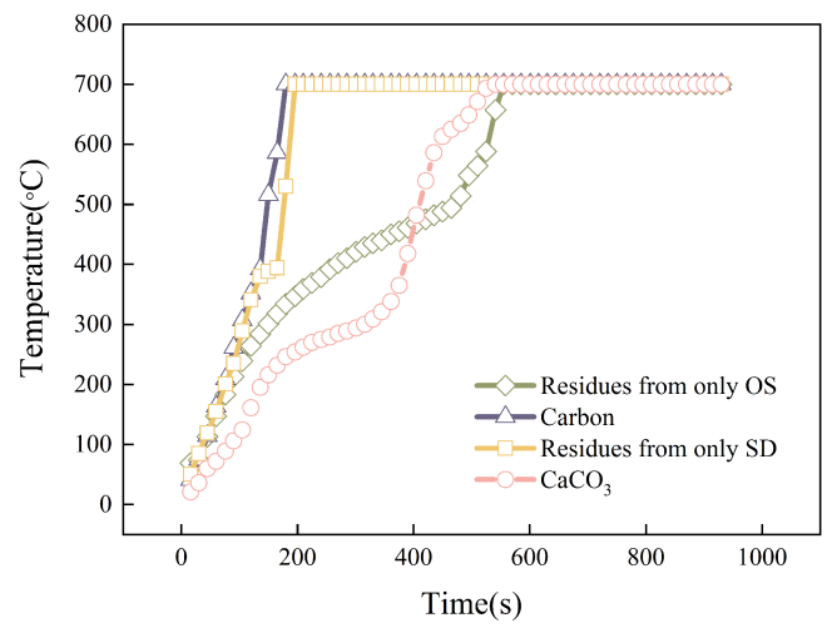

Fig. 6. Temperature profiles of raw materials $(\mathrm{OS} / \mathrm{SD}=1: 1)$ mixed with different additives (additive/raw materials=1:20), including residues from only $\mathrm{SD}$, carbon, residues from only $\mathrm{SD}$ and $\mathrm{CaCO}_{3}$, during microwave co-pyrolysis.

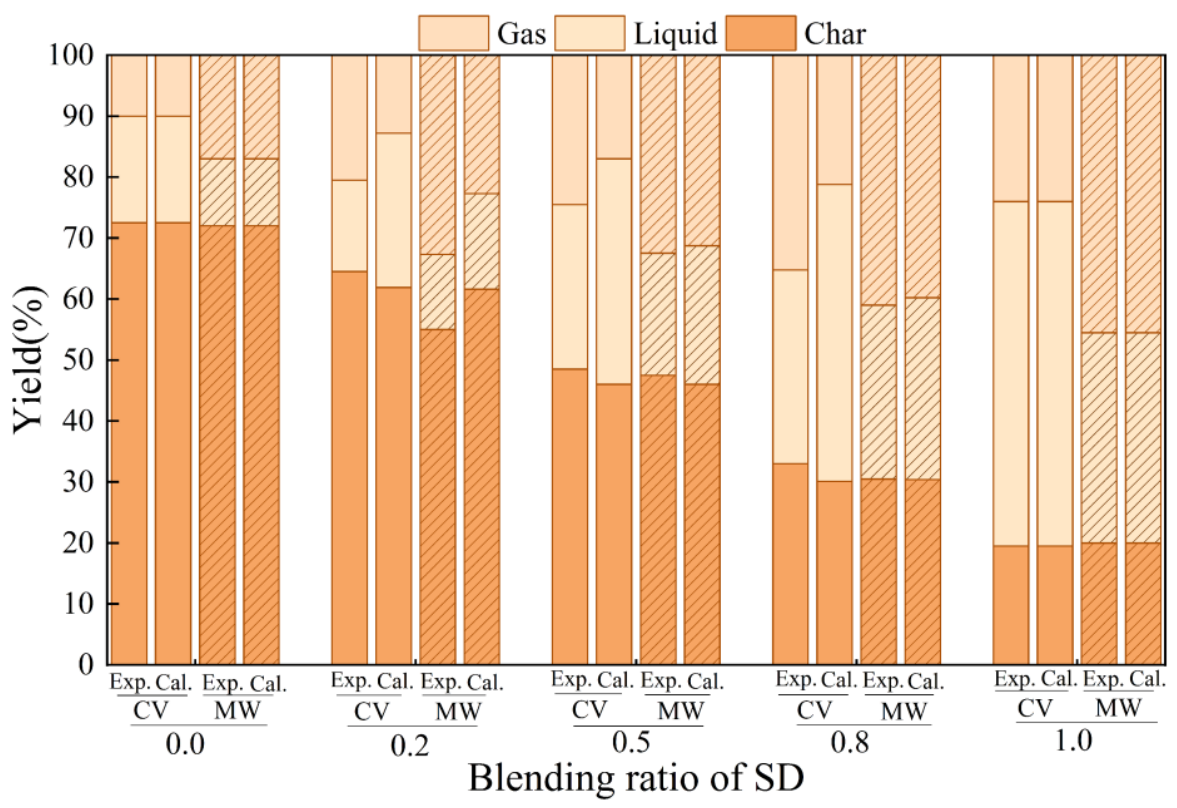

Fig. 7. Product distribution (including experimental and calculated liquid yield, gas yield and char yield) of raw materials (blending ratio of SD is $\mathbf{0 . 0 0 \% , 2 0 . 0 0 \% , 5 0 . 0 0 \% , 8 0 . 0 0 \% , 1 0 0 . 0 0 \% ) ~ d u r i n g ~} \mathrm{CV}$ and MW co-pyrolysis.

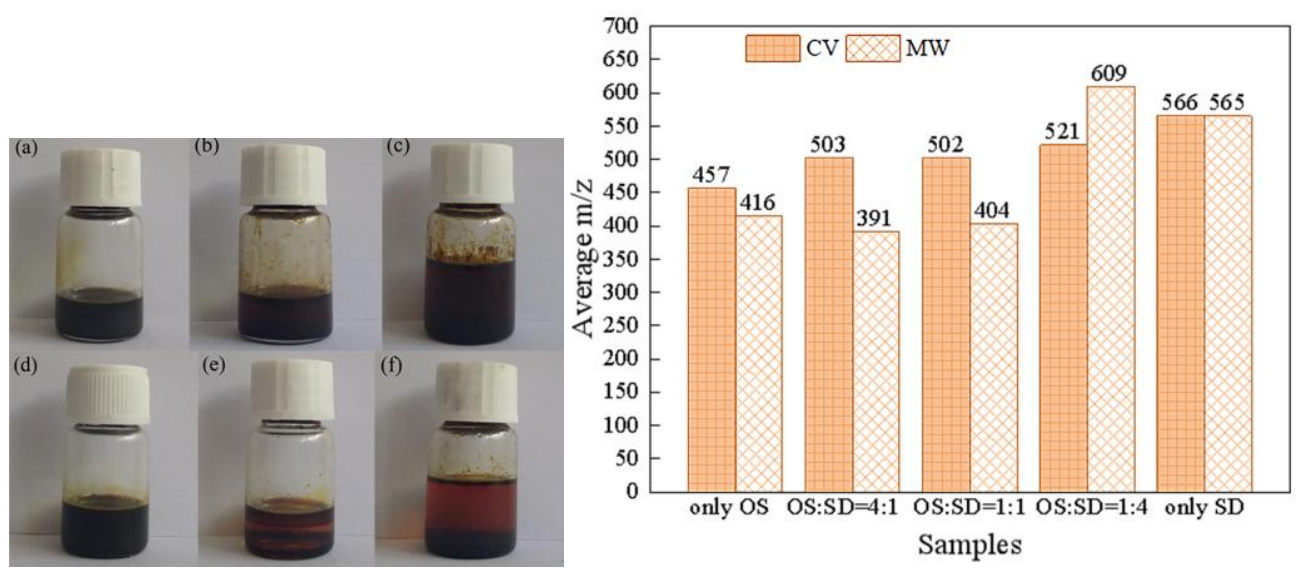


Fig. 8. Liquid products under (a)(b)(c) CV and (d)(e)(f)

MW. (a)(d) only OS, (b)(e) OS:SD=1:1, (c)(f)only SD.
Fig. 9. Average $\mathrm{m} / \mathrm{z}$ of liquid products under $\mathrm{CV}$ and MW pyrolysis.
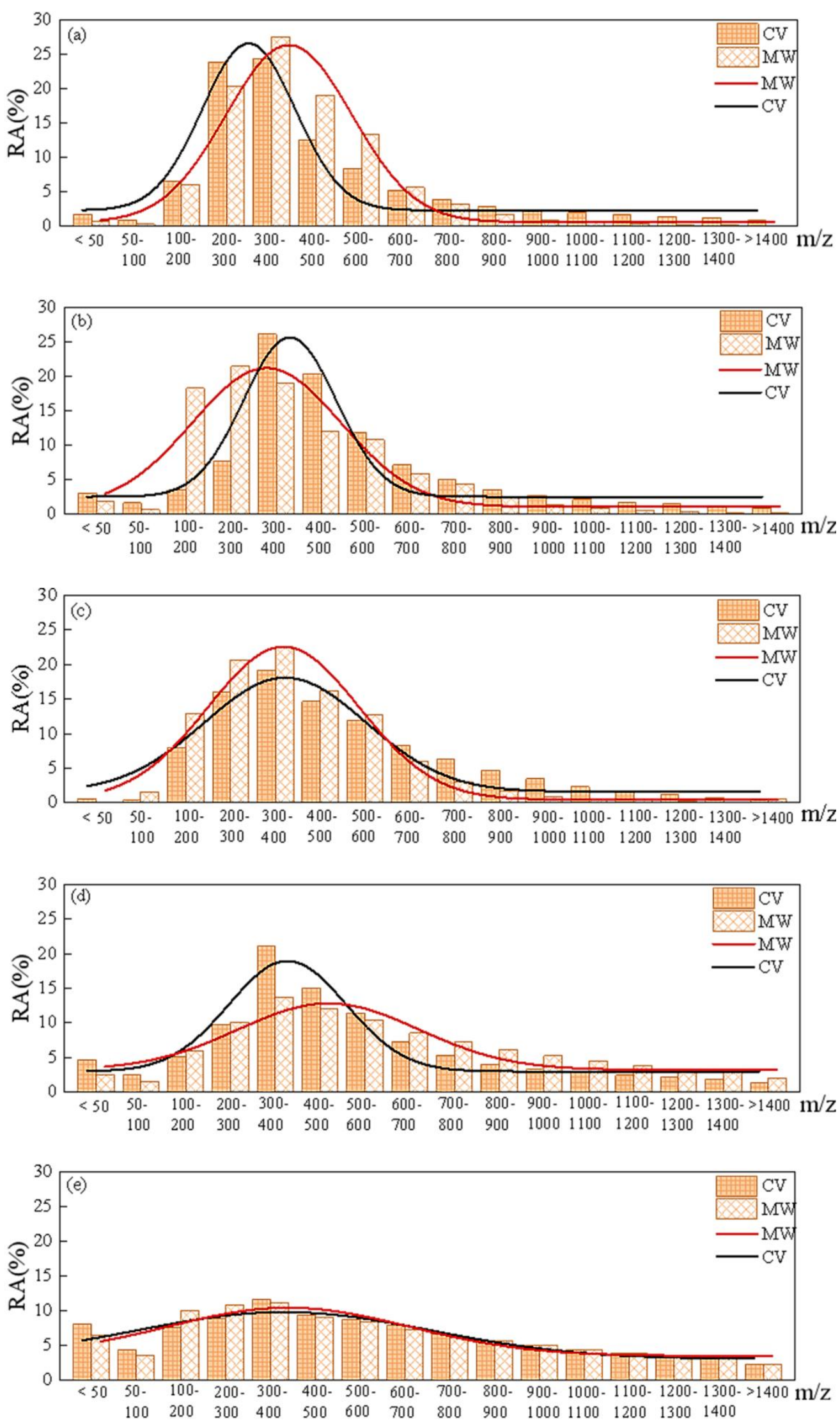
Fig. 10. Molecular weight distributions of liquids under CV and MW pyrolysis.(a) only OS, (b) OS:SD=4:1, (c)OS:SD=1:1, (d)OS:SD=1:4, (e)only SD.

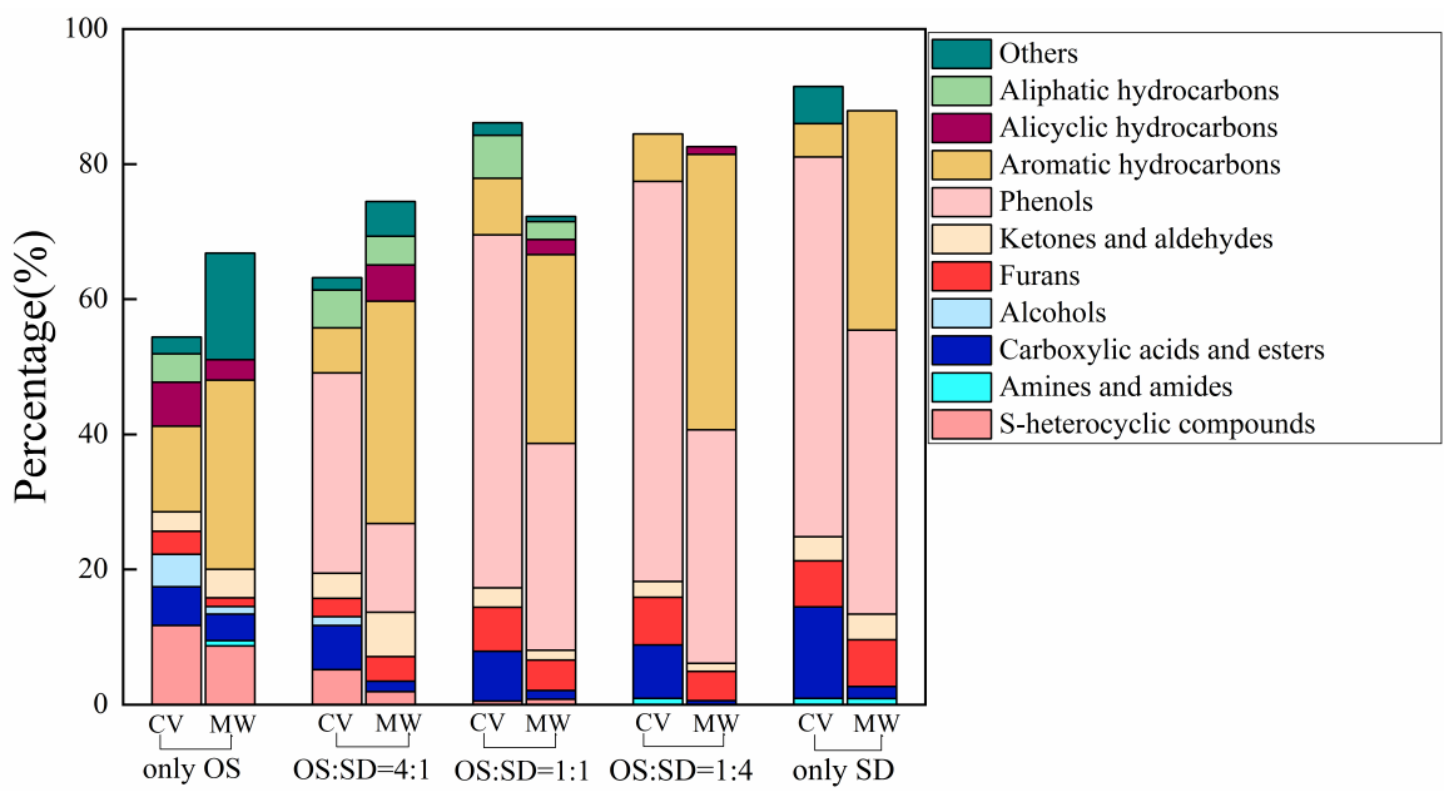

Fig. 11. Percentage contents of component types in co-pyrolysis and individual pyrolysis oil under CV and MW.

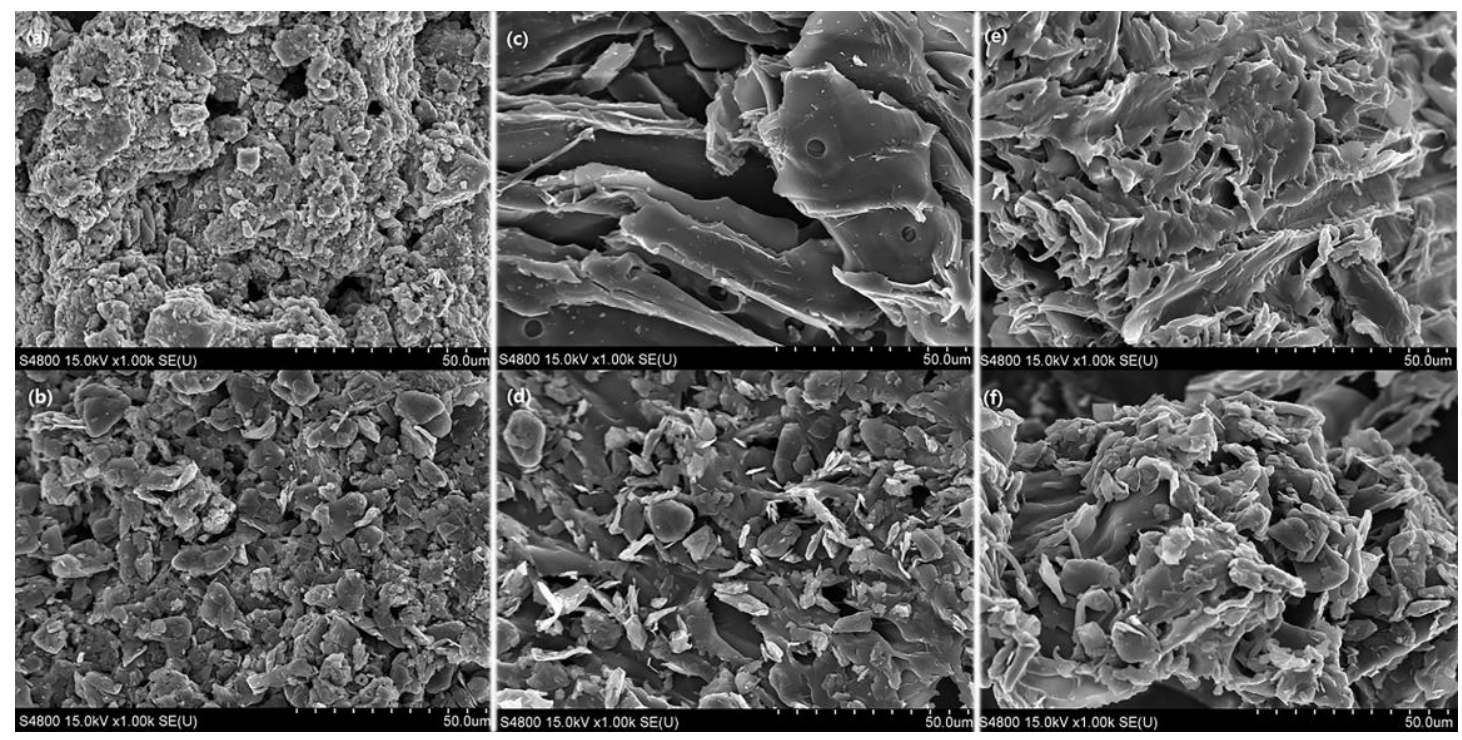

Fig. 12. SEM images of char samples. (a,c,e) under CV pyrolysis, (b,d,f) under MW pyrolysis; (a,b) only OS, (c,d) OS:SD=1:1, (e,f) only SD. 


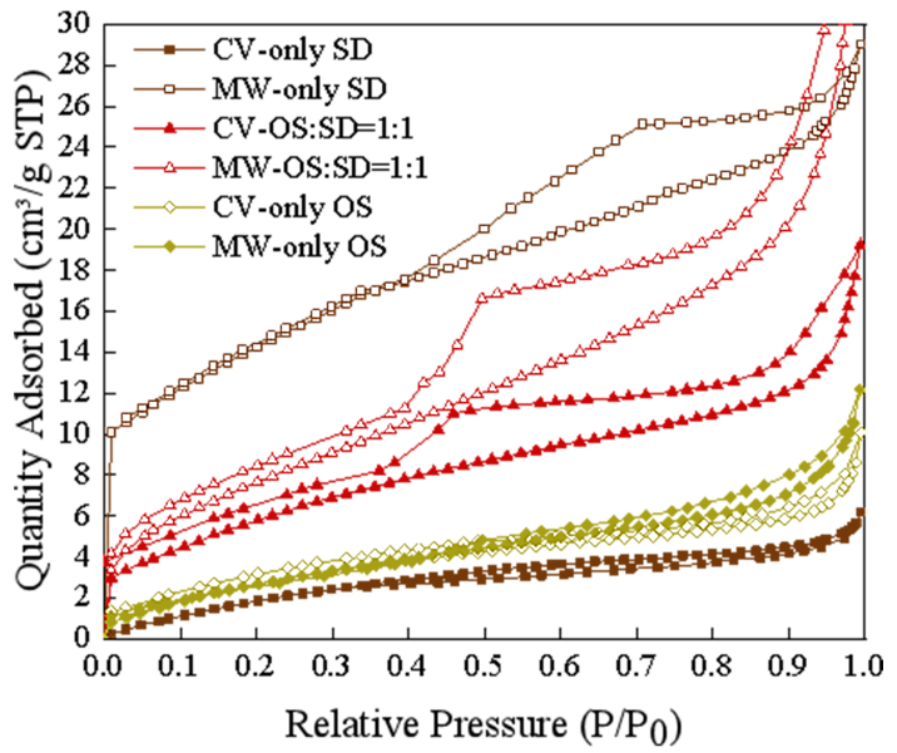

Fig. 13. Adsorption-desorption isotherms of char samples under CV and MW pyrolysis of only SD, $\mathrm{OS}: \mathrm{SD}=1: 1$, only $\mathrm{OS}$.
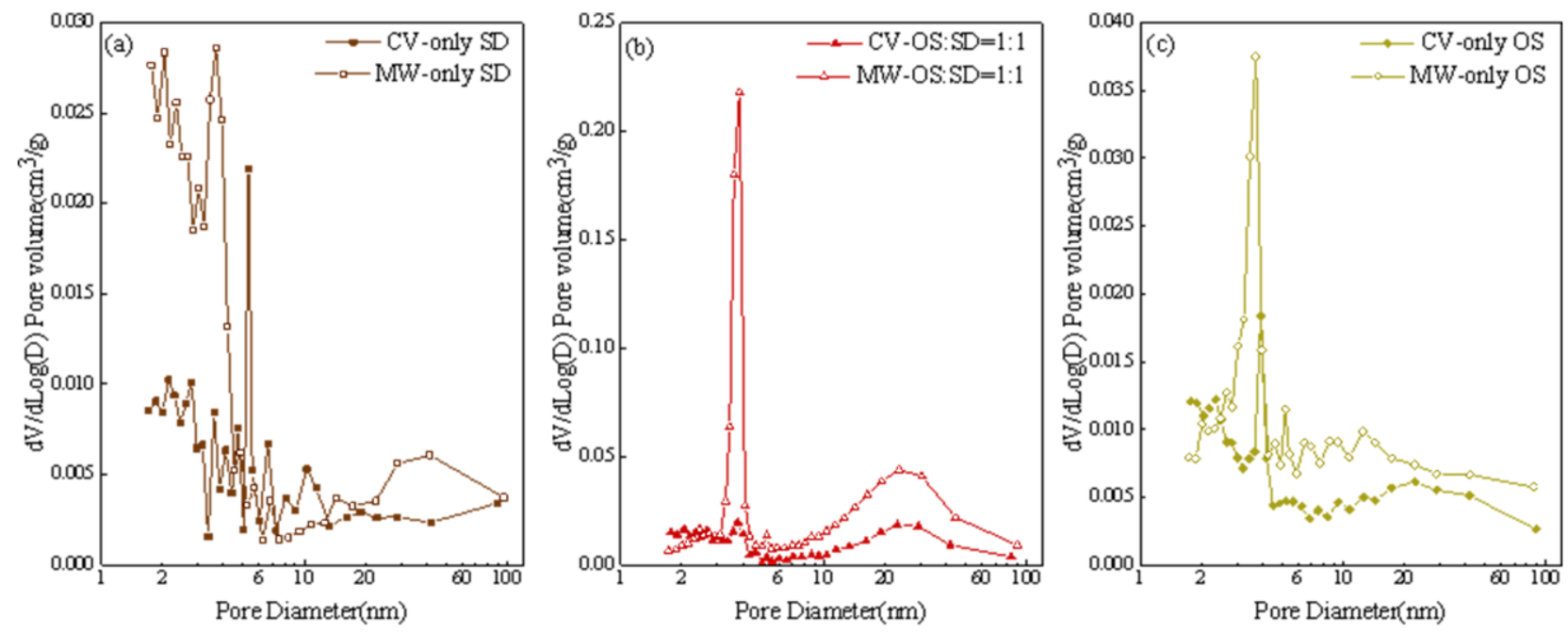

Fig. 14. Pore diameter distributions for char samples under $\mathrm{CV}$ and $\mathrm{MW}$ pyrolysis of only $\mathrm{SD}, \mathrm{OS}: \mathrm{SD}=1: 1$, only OS. 
Supplementary Material
Click here to download Supplementary Material: Supplementary file.doc

Supplementary Material
Click here to download Supplementary Material: Supplementary file.doc

(ile.doc

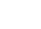

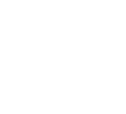

$\sqrt{2}$ (1) (1) (1)

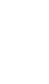
(1) . . .

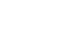

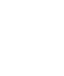

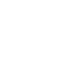

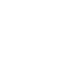

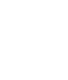

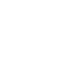

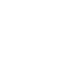

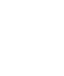
更

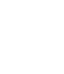

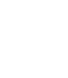

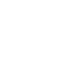

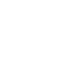

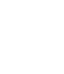

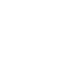

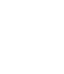

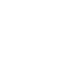

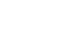

